\title{
Trade Adjustment Dynamics and the Welfare Gains from Trade*
}

\author{
George Alessandria ${ }^{\dagger}$ \\ Federal Reserve Bank of Philadelphia \\ Horag Choi \\ Monash University \\ Kim Ruhl \\ NYU Stern School of Business \\ This Draft: April 2014 \\ First Draft: September 2013
}

\begin{abstract}
We build a micro-founded two-country dynamic general equilibrium model in which trade responds more to a cut in tariffs in the long run than in the short run. The model introduces a time element to the fixed-variable cost trade-off in a heterogeneous producer trade model. Thus, the dynamics of aggregate trade adjustment arise from producer-level decisions to invest in lowering their future variable export costs. The model is calibrated to match salient features of new exporter growth and provides a new estimate of the exporting technology. At the micro level, we find that new exporters commonly incur substantial losses in the first three years in the export market and that export profits are backloaded. At the macro level, the slow export expansion at the producer level leads to sluggishness in the aggregate response of exports to a change in tariffs, with a long-run trade elasticity that is 2.9 times the short-run trade elasticity. We estimate the welfare gains from trade from a cut in tariffs, taking into account the transition period. While the intensity of trade expands slowly, consumption overshoots its new steady-state level, so the welfare gains are almost 15 times larger than the long-run change in consumption. Models without this dynamic export decision underestimate the gains to lowering tariffs, particularly when constrained to also match the gradual expansion of aggregate trade flows.
\end{abstract}

JEL classifications: E31, F12.

Keywords: Sunk cost, fixed cost, establishment heterogeneity, tariff, welfare.

${ }^{*}$ We thank Mark Aguiar, Hal Cole, Richard Rogerson, Virgiliu Midrigan, Mike Waugh and audiences at Clemson, NYU, NBER ITI, the Philadelphia Fed, Princeton, Toronto, and Wharton for helpful comments. The views expressed here are those of the authors and do not necessarily reflect the views of the Federal Reserve Bank of Philadelphia or the Federal Reserve System. This paper is available free of charge at www.philadelphiafed.org/research-and-data/publications/working-papers/.

${ }^{\dagger}$ Corresponding author: george.alessandria@gmail.com, Ten Independence Mall, Philadelphia, PA 19106. 


\section{Introduction}

A robust feature of international trade is that it takes time for trade volumes to fully adjust to changes in trade barriers or relative prices: The trade elasticity, which measures the change in the share of trade in overall expenditures relative to the change in tariffs, increases with the time horizon considered. ${ }^{1}$ Despite widespread agreement that the trade elasticity increases over time, recent theoretical work evaluating the gains from trade largely ignores the effect of this transition on welfare. A rationale for ignoring transitions is that steadystate analyses provide an upper bound on the gains from trade since there is less trade along the transition. ${ }^{2}$ In this paper, we show that this rationale is wrong. Slow trade growth along the transition can lead to larger, not smaller, welfare gains.

We develop the idea that transitions are important for welfare in a micro-founded model in which slow trade growth at the producer level gives rise to slow trade growth at the aggregate level. Our model nests the now-standard models of heterogeneous producers faced with fixed costs of exporting (Krugman 1980, Melitz 2003, Das, Roberts, and Tybout 2007). These models emphasize the trade-off between fixed and variable export costs. Heterogeneity in productivity leads producers to sort into exporters and non-exporters. The discrete nature of the export entry decision in these models, however, generates producer-level dynamics that are at odds with the data. In the data, new exporters initially export a small share of their sales, which then grows slowly with the producer's tenure in the export market (see Figure 1A). In the discrete choice models, when a producer enters the export market, its share of sales that is exported jumps immediately to its long-run value.

A novel feature of our model is that it generalizes the producer's export technology to include a time dimension in the fixed versus variable cost trade-off. As in the standard models, non-exporters can pay a fixed cost to become an exporter, and existing exporters

\footnotetext{
${ }^{1}$ A large empirical literature identifies different short-run and long-run trade responses to aggregate shocks (Hooper, Johnson, and Marquez 2000, Gallaway, McDaniel, and Rivera 2003). Many theoretical studies of the role of trade adjustment explicitly or implicitly calibrate the trade elasticity differently based on the horizon considered, (Obstfeld and Rogoff 2005). Some recent theoretical work has endogenized the dynamics of the trade elasticity, including Alessandria and Choi (2007), Drozd and Nosal (2012), Engel and Wang (2011), Ramanarayanan (2007), Ruhl (2008), and Alessandria, Pratap, and Yue (2013).

${ }^{2}$ Baldwin (1992) shows that the "dynamic" gains from the increased capital accumulation in response to a cut in tariffs are offset by the forgone consumption necessary to support the extra capital stock, unless capital is subject to external economies of scale.
} 
must pay a fixed cost to continue exporting. In contrast to the findings of the existing literature, a producer's capacity for exporting evolves dynamically. As long as exporters remain in the foreign market, the marginal cost of exporting stochastically improves over time: It takes time, resources, and a bit of luck to become an efficient exporter. As producers become more efficient exporters, their export volumes grow, generating the slow expansion of trade at the producer level that we observe in the data.

In the model, the behavior of trade in the aggregate is determined by the behavior of producers: There is no aggregate technology. By disciplining our model of producer-level exporting technology with producer-level data, we avoid making any assumptions about how aggregate trade behaves. In particular, we are not forced to try estimating a trade elasticity that will govern the aggregate behavior of trade - a difficult undertaking given that the trade elasticity is not constant.

In our calibrated model, which generates realistic producer-level export transitions and growth, we study the welfare implications of trade liberalization. The existing literature has largely ignored transitions when computing the welfare gains from trade. The models considered in Arkolakis, Costinot, and Rodríguez-Clare (2012) or Burstein and Melitz (2011), for example, do not have meaningful trade transitions: The models are either static or they jump instantaneously from one steady state to the next. ${ }^{3}$ Our model, which generates a time-varying trade elasticity, demonstrates not only that transitions are important for welfare, but that they also are beneficial. The transition following trade liberalization is a time of increased consumption. The gain in welfare -including the transition period-from a ten-percent cut in tariffs is more than 15 times larger than the steady-state increase in consumption in our benchmark model.

The producer-level dynamics in the transition period following a cut in tariffs generate two competing forces. First, because trade adjusts slowly, producers must make investments in export-specific capacity that will yield increases in exports and profits only in the future. This force reduces the resources available for production and consumption in the short run,

\footnotetext{
${ }^{3}$ Existing models that do generate nontrivial transitions in trade, such as Alessandria and Choi (2007), Engel and Wang (2011), and Drozd and Nosal (2012), have focused on the business cycle properties of the models and have ignored the welfare implications. Alessandria and Choi (2011) do consider transition dynamics in a model without new exporter dynamics.
} 
while improving the efficiency of the economy in the long run. Once tariffs are reduced, the economy has too little export capacity, and the investments that must be made in the transition period act to reduce welfare.

The second force, which gives rise to overshooting in consumption, is a desire to cut back on investments in new varieties. In our framework, varieties are long-lived assets resulting from sunk investments made to create the establishment. When tariffs are reduced, the increased range of varieties from abroad decreases the incentive to invest in accumulating domestic varieties. The desire to run down the stock of domestic varieties frees up resources for production and consumption along the transition, increasing welfare. In the long run, though, the reduced investments in establishments reduce the scale of production, explaining why the change in steady-state consumption is relatively small even though trade grows substantially.

These two forces generate a nonlinear relationship between the trade share and consumption along the transition to the new steady-state following a trade liberalization. In our calibrated model, the consumption gain from running down the overaccumulated stock of varieties is more important than the increased investment in export capacity. Thus, consumption overshoots its steady-state level, and the welfare gains from trade are larger when the transition is taken into account.

We show in Section 6 that producer-level heterogeneity is crucial to understanding the gains from trade and the aggregate trade dynamics from trade liberalization. We do so by constructing a version of our model in which there is no cost to enter the export market, so all producers export, as in Krugman (1980). To keep the aggregate trade dynamics identical across versions of the model, we introduce an adjustment friction and recalibrate the model. While the aggregate trade dynamics in the baseline model and this version of the model are identical, the consumption dynamics are very different. In the model without meaningful producer heterogeneity, consumption grows smoothly during the transition, rather than overshooting as in the baseline model. In this version of the model, the welfare gain is smaller than in the baseline model, even though the steady-state increase in consumption is larger. The results from these experiments imply that the relationship between aggregate trade volumes and consumption - and, thus, welfare - is much more complicated in dynamic 
models than in their static counterparts.

We also show that heterogeneity in export intensity arising from new-exporter dynamics matters for our quantitative results. Eliminating new-exporter growth from our benchmark model reduces it to a GE version of the well-known sunk-cost-of-exporting model developed by Dixit (1989), Baldwin and Krugman (1989), and Das, Roberts, and Tybout (2007). Consistent with Alessandria and Choi (2011), our version of the sunk-cost model also generates overshooting of consumption and a welfare gain that is larger than the change in steadystate consumption. However, the benchmark model with new-exporter dynamics generates a welfare gain that is one-third larger than that of the sunk-cost model, even though the long-run change in consumption in the benchmark model is only one-fifth that of the sunkcost model. The larger welfare gains in the benchmark model arise because, in the transition period, consumption overshoots by more, with a peak gap of almost five percentage points. The bigger boom in consumption occurs even though trade grows much more gradually in the benchmark model than in the sunk-cost model and is, in large part, attributed to a greater desire to run down the stock of new establishments. Thus, we find a larger role for exporter dynamics than in previous work.

In addition to our findings on transitions and welfare, we provide a new estimate of the technology for exporting. We follow the literature in splitting fixed export costs into a sunk entry cost and a continuation cost. Consistent with Ruhl and Willis (2008), we find that with a reasonable exporter lifecycle, the estimated sunk entry cost of exporting is much smaller than those derived from discrete-choice models that ignore new-exporter dynamics. Pushing the returns from exporting into the future reduces the present value of starting to export, so smaller entry costs are needed to match the observed levels of export participation. In contrast to much of the literature, we find that the costs of starting to export are about as large as the costs of continuing to export. This large difference from the literature arises because the continuation cost in our model has an investment component since paying it could further reduce an exporter's future variable cost and increase its future export profits. Indeed, in our model, we find that a new exporter will, on average, earn negative profits in the first few years after starting to export. The losses in these early years arise from the continuation costs being high relative to gross profits from exporting. 
In Section 2, we review the data on the exporter lifecycle, laying out key producerlevel facts used to discipline our model of the producer's exporting technology. In Section 3, we lay out the model, and in Section 4, we describe our strategy for calibrating the model. In Section 5, we report the results from the baseline model and show how the gains from trade liberalization are much larger than the steady-state to steady-state comparisons would suggest. In Section 6, we present alternative versions of the model, highlighting the importance of producer heterogeneity in understanding the welfare gains from trade. The online appendix includes analytical results showing how the steady-state changes with tariffs and iceberg cost.

\section{New-Exporter Dynamics}

At the center of our model is a novel generalization of the specification of the producer's exporting technology. This generalization allows us to capture key facts about exporters that the existing literature has typically ignored. Before laying out the model, we briefly review the data describing the exporter lifecycle that motivate, and, ultimately, will be used to calibrate, our specification of the exporting technology.

New exporters begin by exporting small amounts and increase their exporting activity over several years. Figure 1A, from Ruhl and Willis (2008), plots the average export-total sales ratio of new exporters in Colombia. The average continuing exporter ships 13 percent of its output abroad, while a new exporter ships about six percent of total sales abroad in its first year. It takes five years for the new exporter to reach the same export intensity as the existing exporters. Similar patterns of new exporter behavior are documented in Rho and Rodrigue (2013) and Eaton, Eslava, Krizan, Kugler, and Tybout (2009).

A second important aspect of export entry is evident in Figure 1B, also from Ruhl and Willis (2008). In this figure, we plot the one-period survival rate of exporters conditional on their time in the export market. An export entrant has a 65-percent chance of continuing to export, and this survival rate increases with the time spent as an exporter. The slowly expanding export flows and the high rates of exit imply that export entry is a decision that likely pays off only in the long run-if at all. 


\section{Model}

We develop a dynamic general equilibrium model that captures the lifecycle of both establishments and exporters. There are two symmetric countries: home and foreign. Each country is populated by a unit mass of identical, infinitely-lived consumers that inelastically supply one unit of labor.

In each country, competitive final goods producers purchase home and foreign, $\{H, F\}$, differentiated intermediate inputs. The final good is not traded and is used for consumption, investment, ${ }^{4}$ and as an input into production. There exists a one-period nominal bond denominated in units of the home final good. Let $B_{t}$ denote the home consumer's holding of bonds purchased in period $t$. Let $B_{t}^{*}$ denote the foreign consumer's holding of this bond. The bond pays one unit of home currency in period $t+1$. Let $Q_{t}$ denote the nominal price of the bond $B_{t}$. The home final good is the numeraire, so that its price, $P_{t}=1$. We focus on a symmetric economy with symmetric policies, and, thus, the foreign price level, $P_{t}^{*}=1$, and $B_{t}=0$.

Intermediate goods producers in each country are characterized by their productivity, fixed export cost, and iceberg trade cost. Productivity is stochastic. Iceberg costs have an endogenous and stochastic element, while the fixed cost is endogenous. The shocks to productivity and iceberg costs generate movements of establishments into and out of exporting. Unproductive establishments exit and new establishments enter.

All intermediate goods producers sell to their own country, but only some export. Exporting requires paying a fixed and variable costs. All exporters face the same ad valorem tariff, $\tau$, but differ in their iceberg transportation cost, $\xi \geq 1$, and fixed export costs. The tariff is a policy variable, and the revenues collected from the tariff are rebated lump-sum to the household. The transportation cost is a feature of technology. Fraction $\xi-1$ of an export shipment is destroyed in transit. Fixed export costs are paid in units of domestic labor.

To make the problem most tractable, there are three possible iceberg costs $\xi \in\left\{\xi_{L}, \xi_{H}, \infty\right\}$

\footnotetext{
${ }^{4}$ Capital accumulation is included to more accurately quantify the gains from trade. In most models, capital accumulation tends to increase the steady-state gain from a cut in trade barriers, but makes the steady-state change overstate the welfare gain. Hence, the results are even more surprising.
} 
with $\xi_{L} \leq \xi_{H}<\infty$ and two possible fixed export costs $f \in\left\{f_{L}, f_{H}\right\}, f_{L} \leq f_{H}$. Fixed export costs are related to the variable iceberg costs. Producers with an iceberg cost of $\xi=\infty$ are non-exporters. A non-exporter can lower its next-period iceberg cost to $\xi_{H}$ by paying a $\operatorname{cost} f_{H}$. An exporter with iceberg $\operatorname{costs} \xi_{t}=\left\{\xi_{L}, \xi_{H}\right\}$ can incur a cost $f_{L}$ to draw its nextperiod iceberg cost. We assume that the transition probabilities are Markovian and that the probability of drawing the low iceberg costs, $\xi_{L}$, is lower for an exporter with a high iceberg cost than a producer with a low iceberg cost (i.e., $\left.\rho_{\xi}\left(\xi_{L} \mid \xi_{H}\right) \leq \rho_{\xi}\left(\xi_{L} \mid \xi_{L}\right)\right)$. Thus, part of exporting is making an investment that may lead to a lower marginal cost of exporting in the future. If an exporter does not pay $f_{L}$, its next period iceberg cost rises to $\xi=\infty$.

This formulation of fixed and iceberg costs is quite general and nests the most common approaches to modeling trade. When $f_{L}<f_{H}$, there is a sunk cost of exporting, as in Das, Roberts, and Tybout (2007). When $f_{L}=f_{H}$ and $\xi_{L}=\xi_{H}$, exporting is a static decision. When $f_{L}=f_{H}=0$ and $\xi_{L}=\xi_{H}$, there is no export decision, and this is a general version of the Krugman (1980) model of monopolistic competition.

A potential establishment enters by hiring $f_{E}$ domestic workers and begins producing in the following period. The measure of country $j \in\{H, F\}$ establishments with technology $z$, iceberg costs $\xi$, and fixed costs $f$ is $\varphi_{j, t}(z, \xi, f) .{ }^{5}$ Exit is exogenous and depends on the current productivity level. ${ }^{6}$ The state variable of the economy includes the measure of establishments across individual state variables from each country and the capital stock in each country. For notational ease, economy-wide state variables are subsumed in the time subscript.

\footnotetext{
${ }^{5}$ Here, $f$ is the fixed cost that the producer has to pay if it decides to export, $f=f_{H}$ if $\xi=\infty$ and $f=f_{L}$ otherwise. Note that the producer-specific state is given by $(z, \xi)$. However, we describe producers with $(z, \xi, f)$ to explicitly denote the fixed cost that producers face.

${ }^{6}$ Introducing endogenous exit from a fixed production cost is straightforward and yields similar results to our benchmark model.
} 


\subsection{Consumers}

Home consumers choose consumption, investment, and bonds to maximize utility subject to the sequence of budget constraints,

$$
\begin{aligned}
V_{C, 0} & =\max \sum_{t=0}^{\infty} \beta^{t} U\left(C_{t}\right) \\
C_{t}+K_{t}+Q_{t} B_{t} & \leq W_{t} L_{t}+R_{t} K_{t-1}+(1-\delta) K_{t-1}+B_{t-1}+\Pi_{t}+T_{t},
\end{aligned}
$$

where $\beta \in(0,1)$ is the subjective time discount factor; $C_{t}$ is final consumption; $K_{t-1}$ is the capital available in period $t ; W_{t}$ and $R_{t}$ denote the real wage rate and the rental rate of capital; $\delta$ is the depreciation rate of capital; $\Pi_{t}$ is real dividends from home producers; and $T_{t}$ is the real lump-sum transfer of local tariff revenue. Investment is defined as $I_{t}=K_{t}-(1-\delta) K_{t-1}$.

The foreign consumer's problem is analogous. Foreign prices and allocations are denoted with an asterisk. The foreign budget constraint is

$$
C_{t}^{*}+K_{t}^{*}+Q_{t} B_{t}^{*} \leq W_{t}^{*} L_{t}^{*}+R_{t}^{*} K_{t-1}^{*}+(1-\delta) K_{t-1}^{*}+B_{t-1}^{*}+\Pi_{t}^{*}+T_{t}^{*}
$$

where all prices are quoted in units of the home final good.

The first-order conditions for the consumers' utility maximization problems are

$$
\begin{aligned}
Q_{t} & =\beta \frac{U_{C, t+1}}{U_{C, t}}=\beta \frac{U_{C, t+1}^{*}}{U_{C, t+1}^{*}}, \\
1 & =\beta \frac{U_{C, t+1}}{U_{C, t}}\left(R_{t+1}+1-\delta\right)=\beta \frac{U_{C, t+1}^{*}}{U_{C, t}^{*}}\left(R_{t+1}^{*}+1-\delta\right),
\end{aligned}
$$

where $U_{C, t}$ denotes the derivative of the utility function with respect to its argument.

\subsection{Final Goods Producers}

Final goods are produced by combining home and foreign intermediate goods. The aggregation technology is a CES function

$$
D_{t}=\left\{\sum_{j \in\{H, F\}} \sum_{\xi \in\left\{\xi_{L}, \xi_{H}, \infty\right\}} \int_{z} y_{j, t}^{d}(z, \xi, f)^{\frac{\theta-1}{\theta}} \varphi_{j, t}(z, \xi, f) d z\right\}^{\frac{\theta}{\theta-1}},
$$

where $y_{j, t}^{d}(z, \xi, f)$ are inputs of intermediate goods purchased from country $j$ intermediate producers. The elasticity of substitution between intermediate goods is $\theta>1$. 
The final goods market is competitive. Given the price of inputs, the final goods producer chooses purchases of intermediate inputs, $y_{j, t}^{d}$, to solve

$$
\begin{aligned}
\max \Pi_{F, t}= & D_{t}-\sum_{\xi \in\left\{\xi_{L}, \xi_{H}, \infty\right\}} \int_{z} P_{H, t}(z, \xi, f) y_{H, t}^{d}(z, \xi, f) \varphi_{H, t}(z, \xi, f) d z \\
& -(1+\tau) \sum_{\xi \in\left\{\xi_{L}, \xi_{H}\right\}} \int_{z} P_{F, t}(z, \xi, f) y_{F, t}^{d}(z, \xi, f) \varphi_{F, t}(z, \xi, f) d z
\end{aligned}
$$

subject to the production technology (5). Here, $P_{j, t}(z, \xi, f)$ are the home-country prices of intermediate goods produced in country $j$ establishments. Solving the problem in (6) yields the input demand functions,

$$
\begin{aligned}
& y_{H, t}^{d}(z, \xi, f)=\left[P_{H, t}(z, \xi, f)\right]^{-\theta} D_{t}, \\
& y_{F, t}^{d}(z, \xi, f)=\left[(1+\tau) P_{F, t}(z, \xi, f)\right]^{-\theta} D_{t},
\end{aligned}
$$

where the final goods price is defined as

$P_{t}=\left\{\sum_{\xi \in\left\{\xi_{L}, \xi_{H}, \infty\right\}} \int_{z}\left[P_{H, t}(z, \xi, f)^{1-\theta} \varphi_{H, t}(z, \xi, f)+\left[(1+\tau) P_{F, t}(z, \xi, f)\right]^{1-\theta} \varphi_{F, t}(z, \xi, f)\right] d z\right\}^{\frac{1}{1-\theta}}$.

\subsection{Intermediate Goods Producers}

An intermediate goods producer is described by its technology, iceberg cost, and fixed cost, $(z, \xi, f)$. It produces using capital $k$, labor $l$, and materials $x$ according to a Cobb-Douglas production technology,

$$
y_{t}(z, \xi, f)=e^{z}\left[k_{t}(z, \xi, f)^{\alpha} l_{t}(z, \xi, f)^{1-\alpha}\right]^{1-\alpha_{x}} x(z, \xi, f)^{\alpha_{x}}
$$

The markets that the producer serves in the current period are predetermined, so the producer maximizes current-period gross profits by choosing prices for each market, $P_{H, t}(z, \xi, f)$ and $P_{H, t}^{*}(z, \xi, f)$, labor $l_{t}(z, \xi, f)$, capital $k_{t}(z, \xi, f)$, and materials $x_{t}(z, \xi, f)$, to solve

$$
\begin{aligned}
\Pi_{t}(z, \xi, f) & =\max P_{H, t}(z, \xi, f) y_{H, t}(z, \xi, f)+P_{H, t}^{*}(z, \xi, f) y_{H, t}^{*}(z, \xi, f) \\
& -W_{t} l_{t}(z, \xi, f)-R_{t} k_{t}(z, \xi, f)-P_{t} x_{t}(z, \xi, f)
\end{aligned}
$$


subject to the production technology (9), a constraint that supplies to home and foreign goods markets, $y_{H, t}(z, \xi, f)$ and $y_{H, t}^{*}(z, \xi, f)$, are feasible

$$
y_{t}(z, \xi, f)=y_{H, t}(z, \xi, f)+\xi y_{H, t}^{*}(z, \xi, f),
$$

and the constraints that supplies to home and foreign goods markets are equal to the demands from final good producers from (7) and its foreign analogue,

$$
\begin{aligned}
& y_{H, t}(z, \xi, f)=y_{H, t}^{d}(z, \xi, f) \\
& y_{H, t}^{*}(z, \xi, f)=y_{H, t}^{d *}(z, \xi, f) .
\end{aligned}
$$

Given its downward-sloping demand curve, the monopolistic producer charges a constant markup over marginal cost in each market,

$$
\begin{aligned}
& P_{H, t}(z, \xi, f)=\frac{\theta}{\theta-1} M C_{t} e^{-z} \\
& P_{H, t}^{*}(z, \xi, f)=\frac{\theta}{\theta-1} \xi M C_{t} e^{-z}
\end{aligned}
$$

where

$$
M C_{t}=\alpha_{x}^{-\alpha_{x}}\left(1-\alpha_{x}\right)^{-\left(1-\alpha_{x}\right)}\left[\left(\frac{R_{t}}{\alpha}\right)^{\alpha}\left(\frac{W_{t}}{1-\alpha}\right)^{1-\alpha}\right]^{1-\alpha_{x}}
$$

Note that when $\xi=\infty$, the producer is a non-exporter.

The value of the producer with $(z, \xi)$, if it decides to export in period $t+1$, is

$$
V_{t}^{1}(z, \xi, f)=-W_{t} f+n_{s}(z) Q_{t} \sum_{\xi^{\prime} \in\left\{\xi_{L}, \xi_{H}\right\}} \int_{z^{\prime}} V_{t+1}\left(z^{\prime}, \xi^{\prime}, f_{L}\right) \phi\left(z^{\prime} \mid z\right) \rho_{\xi}\left(\xi^{\prime} \mid \xi\right) d z^{\prime}
$$

and the value of the producer, if it does not export in period $t+1$, is

$$
V_{t}^{0}(z, \xi, f)=n_{s}(z) Q_{t} \int_{z^{\prime}} V_{t+1}\left(z^{\prime}, \infty, f_{H}\right) \phi\left(z^{\prime} \mid z\right) d z^{\prime}
$$

where $n_{s}(z)$ is the probability that the producer survives until the next period. Note that this probability varies with the producer's productivity. The value of the producer is

$$
V_{t}(z, \xi, f)=\Pi_{t}(z, \xi, f)+\max \left\{V_{t}^{1}(z, \xi, f), V_{t}^{0}(z, \xi, f)\right\} .
$$

Clearly, the value of a producer depends on its fixed cost, iceberg cost, and productivity. Given that there are three possible levels of iceberg costs, there are now three possible cutoffs, 
$z_{m, t}$, with $m \in\{L, H, \infty\}$. The critical level of technology for exporting, $z_{m, t}$, satisfies

$$
V_{t}^{1}\left(z_{m, t}, \xi_{m}, f\right)=V_{t}^{0}\left(z_{m, t}, \xi_{m}, f\right)
$$

It is straightforward to show that the threshold for exporting is largest for non-exporters and smallest for exporters with the low iceberg cost $\left(z_{\infty, t}>z_{H, t} \geq z_{L, t}\right)$.

\subsection{Entry}

New establishments are created by hiring $f_{E}$ workers in the period prior to production. Entrants draw their productivity from the distribution $\phi_{E}\left(z^{\prime}\right)$. Entrants cannot export in their first productive period. The free-entry condition is

$$
V_{t}^{E}=-W_{t} f_{E}+Q_{t} \int_{z^{\prime}} V_{t+1}\left(z^{\prime}, \infty, f_{H}\right) \phi_{E}\left(z^{\prime}\right) d z^{\prime} \leq 0
$$

The mass of entrants in period $t$ is $N_{E, t}$, while the mass of incumbents, $N_{t}$, is made up of the two types of exporters and the non-exporters,

$$
\begin{aligned}
N_{L, t} & =\int_{z} \varphi_{H, t}\left(z, \xi_{L}, f_{L}\right) d z \\
N_{H, t} & =\int_{z} \varphi_{H, t}\left(z, \xi_{H}, f_{L}\right) d z \\
N_{\infty, t} & =\int_{z} \varphi_{H, t}\left(z, \infty, f_{H}\right) d z
\end{aligned}
$$

The mass of exporters equals $N_{1, t}=N_{L, t}+N_{H, t}$; the mass of non-exporters equals $N_{0, t}=N_{\infty, t}$; and the mass of establishments equals $N_{t}=N_{1, t}+N_{0, t}$. The fixed costs of exporting imply that only a fraction, $n_{x, t}=N_{1, t} / N_{t}$, of home intermediates are available in the foreign country in period $t$.

Given the critical level of technology for exporters and non-exporters, $z_{m, t}$, the starter ratio, the fraction of establishments among non-exporters that start exporting, and the stopper ratio, the fraction of exporters among surviving establishments who stop exporting, 
are, respectively,

$$
\begin{aligned}
n_{0, t+1} & =\frac{\int_{z_{\infty, t}}^{\infty} n_{s}(z) \varphi_{H, t}\left(z, \infty, f_{H}\right) d z}{\int_{z} n_{s}(z) \varphi_{H, t}\left(z, \infty, f_{H}\right) d z}, \text { and } \\
n_{1, t+1} & =\frac{\sum_{m \in\{L, H\}} \int_{-\infty}^{z_{m, t}} n_{s}(z) \varphi_{H, t}\left(z, \xi_{m}, f_{L}\right) d z}{\sum_{m \in\{L, H\}} \int_{z} n_{s}(z) \varphi_{H, t}\left(z, \xi_{m}, f_{L}\right) d z}
\end{aligned}
$$

The mass of establishments evolves according to

$$
\begin{aligned}
\varphi_{t+1}\left(z^{\prime}, \infty, f_{H}\right) & =\sum_{m \in\{L, H, \infty\}} \int_{-\infty}^{z_{m, t}} n_{s}(z) \varphi_{H, t}\left(z, \xi_{m}, f\right) \phi\left(z^{\prime} \mid z\right) d z+N_{E, t} \phi_{E}\left(z^{\prime}\right) \\
\varphi_{t+1}\left(z^{\prime}, \xi_{H}, f_{L}\right) & =\sum_{m \in\{L, H, \infty\}} \rho_{\xi}\left(\xi_{H} \mid \xi_{m}\right) \int_{z_{m, t}}^{\infty} n_{s}(z) \varphi_{H, t}\left(z, \xi_{m}, f\right) \phi\left(z^{\prime} \mid z\right) d z \\
\varphi_{t+1}\left(z^{\prime}, \xi_{L}, f_{L}\right) & =\sum_{m \in\{L, H, \infty\}} \rho_{\xi}\left(\xi_{L} \mid \xi_{m}\right) \int_{z_{m, t}}^{\infty} n_{s}(z) \varphi_{H, t}\left(z, \xi_{m}, f\right) \phi\left(z^{\prime} \mid z\right) d z
\end{aligned}
$$

\subsection{Government and Aggregate Variables}

The government collects tariffs and redistributes the revenue lump sum to domestic consumers. The government's budget constraint is

$$
T_{t}=\tau \sum_{\xi \in\left\{\xi_{L}, \xi_{H}\right\}} \int_{z} P_{F, t}\left(z, \xi, f_{L}\right) y_{F, t}\left(z, \xi, f_{L}\right) \varphi_{F, t}\left(z, \xi, f_{L}\right) d z .
$$

Nominal exports and imports are defined as

$$
\begin{aligned}
E X_{t}^{N} & =\sum_{\xi \in\left\{\xi_{L}, \xi_{H}\right\}} \int_{z} P_{H, t}^{*}\left(z, \xi, f_{L}\right) y_{H, t}^{*}\left(z, \xi, f_{L}\right) \varphi_{H, t}\left(z, \xi, f_{L}\right) d z, \text { and } \\
I M_{t}^{N} & =\sum_{\xi \in\left\{\xi_{L}, \xi_{H}\right\}} \int_{z} P_{F, t}\left(z, \xi, f_{L}\right) y_{F, t}\left(z, \xi, f_{L}\right) \varphi_{F, t}\left(z, \xi, f_{L}\right) d z
\end{aligned}
$$

respectively. Home nominal GDP is the sum of value added from intermediate and final goods producers, which equals $Y_{t}^{N}=C_{t}+I_{t}+E X_{t}^{N}-I M_{t}^{N}$. The trade-to-GDP ratio is

$T R_{t}=\frac{E X_{t}^{N}+I M_{t}^{N}}{2 Y_{t}^{N}}$. Let $I M D_{t}$ be the expenditure on imported goods relative to that on home goods:

$$
I M D_{t}=\frac{\left(1+\tau_{t}\right) \sum_{\xi \in\left\{\xi_{L}, \xi_{H}\right\}} \int_{z} P_{F, t}\left(z, \xi, f_{L}\right) y_{F, t}\left(z, \xi, f_{L}\right) \varphi_{F, t}\left(z, \xi, f_{L}\right) d z}{\sum_{\xi \in\left\{\xi_{L}, \xi_{H}, \infty\right\}} \int_{z} P_{H, t}(z, \xi, f) y_{H, t}(z, \xi, f) \varphi_{H, t}(z, \xi, f) d z}
$$


We define the share of expenditures on domestic goods as

(34) $\lambda_{t}=\frac{1}{1+I M D_{t}}$,

and the trade elasticity as

(35) $\varepsilon_{t}=-\frac{\ln \left(I M D_{t} / I M D_{-1}\right)}{\ln \left(\left(1+\tau_{t}\right) /\left(1+\tau_{-1}\right)\right)}$.

Production labor, $L_{P, t}$, equals

$$
L_{P, t}=\sum_{\xi \in\left\{\xi_{L}, \xi_{H}, \infty\right\}} \int_{z} l_{t}(z, \xi, f) \varphi_{H, t}(z, \xi, f) d z
$$

The domestic labor hired by exporters to cover the fixed costs of exporting, $L_{X, t}$, equals

$$
L_{X, t}=\sum_{m \in\{L, H\}} f_{L} \int_{z_{m, t}}^{\infty} \varphi_{H, t}\left(z, \xi_{m}, f_{L}\right) d z+f_{H} \int_{z_{\infty, t}}^{\infty} \varphi_{H, t}\left(z, \infty, f_{H}\right) d z
$$

From (37), we see that the trade cost, measured in units of domestic labor, depends on the exporter status from the previous period. Aggregate profits equal the difference between profits and fixed costs,

$$
\Pi_{t}=\sum_{\xi \in\left\{\xi_{L}, \xi_{H}, \infty\right\}} \int_{z} \Pi_{t}(z, \xi, f) \varphi_{H, t}(z, \xi, f) d z-W_{t} L_{X, t}-W_{t} f_{E} N_{E, t}
$$

\subsection{Equilibrium Definition}

In an equilibrium, variables satisfy several resource constraints. The final goods marketclearing conditions are $D_{t}=C_{t}+I_{t}+X_{t}$, and $D_{t}^{*}=C_{t}^{*}+I_{t}^{*}+X_{t}^{*}$, where $X_{t}$ is the total material inputs in production given by

$$
X_{t}=\sum_{\xi \in\left\{\xi_{L}, \xi_{H}, \infty\right\}} \int_{z} x_{t}(z, \xi, f) \varphi_{H, t}(z, \xi, f) d z
$$

Each individual goods market clears; the labor market-clearing conditions are $L=L_{P, t}+$ $L_{X, t}+f_{E} N_{E, t}$ and the foreign analogue; the capital market-clearing conditions are

$$
K_{t-1}=\sum_{\xi \in\left\{\xi_{L}, \xi_{H}, \infty\right\}} \int_{z} k_{t}(z, \xi, f) \varphi_{H, t}(z, \xi, f) d z,
$$

and the foreign analogue. The government budget constraint is given by (30) and the foreign analogue. The profits of establishments are distributed to the shareholders, $\Pi_{t}$, and the foreign analogue. The international bond market-clearing condition is given by $B_{t}+B_{t}^{*}=0$. Finally, writing the budget constraints in units of local currency permits us to normalize the 
price of consumption in each country as $P_{t}=P_{t}^{*}=1$.

An equilibrium of the economy is a collection of allocations for home consumers $C_{t}, B_{t}$, and $K_{t}$; allocations for foreign consumers $C_{t}^{*}, B_{t}^{*}$, and $K_{t}^{*}$; allocations for home final goods producers; allocations for foreign final goods producers; allocations, prices, and export decisions for home intermediate producers; allocations, prices, and export decisions for foreign intermediate producers; labor used for exporting costs and for entry costs by home and foreign producers; transfers $T_{t}, T_{t}^{*}$ by home and foreign governments; real wages $W_{t}, W_{t}^{*}$, real rental rates of capital $R_{t}, R_{t}^{*}$, and bond prices $Q_{t}$ that satisfy the following conditions: (i) the consumer allocations solve the consumer's problem; (ii) the final good producers' allocations solve their profit-maximization problems; (iii) intermediated good producers' allocations, prices, and export decisions solve their profit-maximization problems; (iv) the entry conditions holds; (v) the market-clearing conditions hold; and (vi) the transfers satisfy the government budget constraint.

\section{Calibration}

The model is calibrated to match features of the US economy. We first describe the functional forms and parameter values of our benchmark economy. The parameter values used in the simulation exercises are reported in Table 1.

The instantaneous utility function is $U(C)=\frac{C^{1-\sigma}}{1-\sigma}$, where $1 / \sigma$ is the intertemporal elasticity of substitution. The discount factor, $\beta$, depreciation rate, $\delta$, and risk aversion, $\sigma$, are standard, $\beta=0.96, \delta=0.10$, and $\sigma=2$. Labor supply is normalized to 1 .

The distribution of establishments is determined by the structure of shocks. To eliminate the role of the elasticity of substitution $\theta$ in establishment dispersion, we assume that producer productivity $z=\frac{1}{\theta-1} \ln a$. An incumbent's productivity has an autoregressive component $(\rho<1)$ of $\ln a^{\prime}=\rho \ln a+\varepsilon, \varepsilon \stackrel{i i d}{\sim} N\left(0, \sigma_{\varepsilon}^{2}\right)$. With an $\operatorname{AR}(1)$ shock process, the conditional distribution is normal, $\phi\left(\ln a^{\prime} \mid \ln a\right)=N\left(\rho \ln a, \sigma_{\varepsilon}^{2}\right)$, and the unconditional distribution is $N\left(0, \frac{\sigma_{\varepsilon}^{2}}{1-\rho^{2}}\right)$. Entrants draw productivity based on the unconditional distribution $\ln a^{\prime}=\mu_{E}+\varepsilon_{E}, \varepsilon_{E} \stackrel{i i d}{\sim} N\left(0, \frac{\sigma_{\varepsilon}^{2}}{1-\rho^{2}}\right)$, where $\mu_{E}<0$ is chosen to match the observation that entrants are smaller than incumbents. Establishments receive an exogenous death shock that 
depends on an establishment's last-period productivity, $a$, so that the probability of death is $n_{d}(a)=1-n_{s}(a)=\max \left\{0, \min \left\{e^{-\lambda a}+n_{d 0}, 1\right\}\right\}$.

The parameter $\theta$ determines both the producer's markup and the elasticity of substitution across varieties. We set $\theta=5$ to yield a producer markup of 25 percent. We set the tariff rate to ten percent to include the direct measure of tariff and non-tariff barriers.

Recall that four parameters determine the dynamics of export intensity: the two iceberg $\operatorname{costs}\left\{\xi_{H}, \xi_{L}\right\}$ and the transition probabilities, which we denote $\left\{\rho_{L L}, \rho_{H H}\right\}$. For simplicity, we assume that $\rho_{L L}=\rho_{H H}=\rho_{\xi}$, so that three parameters determine the trade intensity dynamics.

The labor share parameter in production, $\alpha$, is set to match the labor income to GDP ratio of 66 percent. In the model, $\alpha_{x}$ determines the ratio of value-added to gross output in manufacturing. In the United States, this ratio averaged 2.8 from 1987 to 1992 and implies that $\alpha_{x}=0.810$. The entry cost, $f_{E}$, is set to normalize the total mass of establishments, $N$, to 1 . The mean establishment size is normalized to the US in 1992.

The ten parameters, $\left\{\lambda, n_{d}, \rho_{z}, \sigma_{z}^{2}, \mu_{E}, f_{L}, f_{H}, \xi_{L}, \xi_{H}, \rho_{\xi}\right\}$, are chosen to match the following observations:

1. Export intensity of 13.3 percent (based on the 1992 U.S. Census of Manufactures, CM).

2. Initial export intensity that is half of the mean export intensity (Ruhl and Willis 2008).

3. Export intensity in year five is twice the export intensity in initial year (Ruhl and Willis 2008).

4. An exporter rate of 22.3 percent (1992 CM).

5. A stopper rate of 17 percent as in Bernard and Jensen (1999), based on the Annual Survey of Manufactures (ASM) of the Bureau of the Census, 1984-1992.

6. Five-year exit rate for entrants of 37 percent (Dunne, Roberts, and Samuelson 1989).

7. Entrants' labor share of 1.5 percent reported in Davis, Haltiwanger, and Schuh (1998), based on the ASM.

8. Shut-down establishments' labor share of 2.3 percent (Davis, Haltiwanger, and Schuh 1998).

9. Establishment employment size distribution as in the $1992 \mathrm{CM}$. 
Table 1: Model Parameters

\begin{tabular}{cccc}
\hline \hline \multicolumn{4}{c}{ Common parameters } \\
$\beta$ & $\sigma$ & $\delta$ & $\tau$ \\
0.96 & 2.0 & 0.10 & 0.10 \\
\multicolumn{4}{c}{ Model-specific parameters } \\
& Benchmark & Sunk-Cost & No-Cost \\
\hline$\theta$ & 5.00 & 5.00 & 12.54 \\
$\alpha$ & 0.132 & 0.132 & 0.276 \\
$\alpha_{m}$ & 0.810 & 0.810 & 0.704 \\
$\lambda$ & 21.04 & 21.04 & 21.04 \\
$n_{d 0}$ & 0.0226 & 0.0226 & 0.0226 \\
$\rho_{z}$ & 0.654 & 0.654 & 0.654 \\
$\sigma_{\varepsilon}$ & 1.32 & 1.32 & 1.32 \\
$\mu_{E}$ & -1.34 & -1.34 & -1.34 \\
$\theta f_{E}$ & 32.7 & 33.2 & 34.7 \\
$f_{H} / f_{E}$ & 0.0376 & 0.0579 & 0.000 \\
$f_{L} / f_{E}$ & 0.0269 & 0.0152 & 0.000 \\
$\xi_{H}$ & 1.718 & 1.430 & 1.112 \\
$\xi_{L}$ & 1.07 & 1.430 & 1.112 \\
$\rho_{\xi}$ & 0.916 & 1.000 & 1.000 \\
\hline \hline
\end{tabular}

The first three targets summarize the dynamics of export intensity and determine the technology for shipping $\left(\xi_{L}, \xi_{H} \rho_{\xi}\right)$. The next two targets relate exporters to the population of establishments and largely determine the fixed costs, $\left(f_{L}, f_{H}\right)$. The next three targets help pin down the establishment creation, destruction, and growth process $\left(\rho_{z}, \sigma_{\varepsilon}, \lambda, \mu_{E}, n_{d}\right)$. Newborn establishments and dying establishments tend to have few employees. Moreover, newborns have high failure rates. Finally, we minimize the distance between the model and empirical distribution of US establishments.

The calibration provides an estimate of the establishment creation and exporting technologies. The cost of starting to export is relatively small, only 3.7 percent of the cost of creating an establishment, but it is about 40-percent larger than the cost of continuing to export (0.246 vs 0.176$)$. The high iceberg $\operatorname{cost} \xi_{H}$ is estimated to be about 63-percent larger than the low $\operatorname{cost} \xi_{L}$ (1.718 vs 1.084), and the idiosyncratic iceberg cost is quite persistent, $\rho_{\xi}=0.916$.

Figure $2 \mathrm{~A}$ shows how the average export intensity, measured as the ratio of export revenue 
to total revenue, rises with years of exporting based on our ergodic distribution. It shows that export intensity grows gradually beyond the five-year period being targeted. This reflects a rising probability that a long-term exporter has the low iceberg cost. Figure 2B shows that the probability of continuing in the export market rises over time after the second year in the market, consistent with the Colombian data in Figure 1B. This primarily reflects the fact that older exporters are more likely to have become efficient exporters and are less willing to give this up by exiting. This model outcome was not targeted and provides independent validation of the model. These two figures are consistent with evidence from Ruhl and Willis (2008).

The low export intensity and continuation probabilities suggest that export profits are quite low initially and rise over time. Panel $\mathrm{C}$ shows how the net profits of a marginal starter (i.e., a producer with productivity $\mathrm{z}_{\infty}$ in period 0 ) evolve over time when it is hit by shocks that lead it to continue exporting $\left(\prod_{j=1}^{t} \pi_{t}>0\right)$. In this figure, we plot

$$
\mu_{t}=100 * \frac{E\left(\pi_{t}-f_{t} \mid \pi_{j}>0, j=1, . ., t\right)}{f_{0}}
$$

In the year prior to exporting, $\mu_{0}=-100$ since the producer pays $f_{H}$ and earns $\pi_{0}=0$. This measure of net profits to entry costs is rising with time in the market, primarily because older exporters tend to be more-efficient exporters. Given this profile of gross profits, a new marginal exporter expects to have negative net profits over its first three years in the market, in addition to the loss incurred in the year prior to entry. Over this period, the new exporter is willing to lose money in order to have the chance to become an efficient exporter in the future. This investment is risky, as many new exporters exit right away.

Eliminating the variance in iceberg costs, $\xi_{L}=\xi_{H}=\xi$, yields the traditional sunk cost model of Das, Roberts, and Tybout (2007), studied in general equilibrium in Alessandria and Choi (2011). We report the parameter estimates from this version of the model in the column "sunk-cost" in Table 2. In this case, the iceberg cost is estimated to be $\xi=1.43$, and the export entry cost is estimated to be 3.8 times the cost of continuing to export. In this model, the cost of starting an establishment is 1.5-percent higher than in the benchmark model. In the sunk-cost model, an important reason that exporters stay in the market is 
to avoid paying the large up-front cost of re-entering. In the benchmark model, this effect is much smaller since the gap between the startup and continuation costs is small. Rather, exporters stay in the market to maintain access to the good exporting technology, $\xi_{L}$, and to avoid going through the growth process again.

To show how the timing of profits depends on the structure of trade costs, we take the export decisions of the marginal new exporter in the benchmark model, which we considered in $2 \mathrm{C}^{7}$ We then assume that this new exporter faces the trade costs from the sunk-cost model, but that it uses the same exit decisions as in the benchmark model. In this way, we can see how the path of expected profits varies with the years exporting for a particular path of productivity and participation. To make profits comparable across models, net profits are measured relative to the export entry cost from the benchmark model. Figure $2 \mathrm{C}$ shows that, with the sunk-cost export technology, the up-front investment to enter is about twice as large, and the producer starts earning a net profit from the first period in the market. This partly reflects a much higher initial export intensity and a smaller continuation cost (about half that of our benchmark model). Over time, the profit rate does not change much. Comparing the models, the sunk-cost model front-loads the costs and benefits from exporting relative to the benchmark model. The rising net profits in the benchmark model make it clear that the continuation cost in that model is primarily an investment in lowering the future marginal cost of exporting. Figure 2D reports the cumulative profits in both models. It takes almost seven years for the cumulative net profits in the benchmark model to exceed the net profits in the sunk-cost specification.

\section{Results}

We now consider the impact of a change in tariffs on welfare and the dynamics of trade. In particular, we assume an unanticipated elimination of the ten-percent tariff. We focus on an unanticipated change in tariffs to clarify the aggregate effect of tariffs. It is straightforward to consider the more empirically relevant case of anticipated changes in trade policy.

Table 2 reports the changes in welfare and trade. Figure 3 plots the dynamics of some key

\footnotetext{
${ }^{7}$ Obviously, this producer would make different exit decisions in this sunk-cost environment.
} 
variables. Even though trade grows gradually, consumption booms during the transition, so the welfare gains are about 15 times larger than the change in steady-state consumption (6.30 vs 0.42 ). Thus, the conventional view that slow trade adjustment should lower the gains to trade liberalization does not hold in the model with endogenous export participation and exporter growth.

With lower tariffs, trade expands substantially, rising from 9.7 percent of manufacturing shipments to 29.2 percent. Figure 3A shows that this expansion takes time, as the trade elasticity grows slowly. In the first year, only the intensive margin operates, so the trade elasticity is equal to $\theta-1$. With time, as more exporters enter, continue, and mature, export shipments expand. Ten years after the policy change, the endogenous part of the trade elasticity $^{8}$ has increased only by 69 percent of its long-run change: Trade is quite sluggish.

One way to measure the sluggishness in trade is to measure the discounted average trade elasticity as

(42) $\bar{\varepsilon}_{t}=(1-\beta) \sum_{t=0}^{\infty} \beta^{t} \varepsilon_{t}$.

This measure weights the early periods of trade adjustment more than later periods and provides a relevant measure of the speed of trade adjustment. It also is a simple way to compare trade dynamics across models. In our model, the short-run elasticity is four; the discounted trade elasticity is 10.15; and the long-run elasticity is 11.55 .

Sluggish trade growth does not lead to very sluggish growth in consumption or output (see Figure 3B). Consumption and output jump initially. Consumption has a hump shape, peaking seven years after the policy change and 9.75 percentage points above the long-run change, which is a relatively moderate increase of 0.42 percentage point. Figure $3 \mathrm{C}$ shows how different forms of investment change during the transition to the new steady-state. Investment in capital initially falls and then recovers strongly as the economy uses capital to smooth out the benefits of the policy. Capital dynamics imply that output expands a bit more strongly than consumption. Investment in establishment creation falls in the first few years and then recovers to a lower level of establishment creation. The stock of

\footnotetext{
${ }^{8} \mathrm{By}$ the endogenous component, we mean the part due to entry and exit rather than to the intensive margin.
} 
establishments falls gradually to the new steady-state.

The desire to reduce the number of establishments following the policy change is key to the overshooting behavior in the model since it implies that more resources are initially available for production along the transition (see Figure 3C) and that there is a large stock of establishments that can be converted to exporting. The decline in establishments is gradual because the overshooting in aggregate economic activity increases profits enough to offset the negative effect of increased trade on entry. This is a similar mechanism to that discussed by Alessandria and Choi (2011) with only a sunk cost. Chaney (2005) and Burstein and Melitz (2011) also argue for overshooting in consumption, but in their framework, with no dynamic exporting decision or capital accumulation, the overshooting arises because of a sharp drop in entry.

The effect of the decline in establishment creation on the aggregate dynamics of the economy can be seen most clearly in a counterfactual experiment in which the mass of entrants does not change. For this experiment, it is assumed that the entry cost receives a subsidy $\tau_{t}^{E}$ financed by a lump-sum tax that keeps $N_{t}=1$. Figure 4 plots the dynamics of the trade elasticity and consumption in this counterfactual and the benchmark model. With no change in establishment creation, trade expands by less, as exporters are discouraged from entering in the face of greater local competition. Consumption declines slightly in the first period, owing to the investments in expanding export participation. It then grows monotonically to the new steady-state level, which is seven percentage points above the level in the benchmark model (7.41 vs 0.42 ). It takes 20 years for this alternative model to reach the same level of consumption as in the benchmark model.

\section{Sensitivity}

To evaluate the role of producer-level export dynamics for the aggregate effect of tariffs, we consider two variations of the benchmark economy. First, we eliminate the sluggishness in producer-level export growth. This variation of the sunk-cost model of Das, Roberts, and Tybout (2007) clarifies the role of the growth in exporter intensity on the aggregate economy. Next, we examine how well a model without an export decision that is calibrated 
Table 2: Effect of a Cut in Tariffs of 10 Percentage Points

\begin{tabular}{lcccc}
\hline \hline Change & Benchmark & Sunk-Cost & $\begin{array}{c}\text { No-Cost- } \\
\text { No Sluggish }\end{array}$ & No-cost \\
\hline Welfare gain & 6.30 & 4.75 & 3.34 & 2.34 \\
Consumption & 0.42 & 1.98 & 3.93 & 3.93 \\
Discounted trade elasticity & 10.15 & 6.90 & 11.55 & 10.15 \\
Trade elasticity & 11.55 & 7.19 & 11.55 & 11.55 \\
\hline \hline
\end{tabular}

Note: Welfare gain is a value of $x$ that satisfies $\sum_{t=0}^{\infty} \beta^{t} U\left(C_{-1} e^{x}\right)=\sum_{t=0}^{\infty} \beta^{t} U\left(C_{t}\right)$, where $C_{-1}$ is the consumption level in the initial steady state. The discounted trade elasticity is $\bar{\varepsilon}=(1-\beta) \sum_{t=0}^{\infty} \beta^{t} \varepsilon_{t}$, where $\varepsilon_{t}$ is the trade elasticity based on the difference in trade between period $t$ and the initial steady state. The long-run trade elasticity is $\lim _{t \rightarrow \infty} \varepsilon_{t}$.

to get the same aggregate export growth along the transition and in the new steady-state approximates the results in our benchmark model. This allows us to explore how well the idea from Arkolakis, Costinot, and Rodríguez-Clare (2012) — that the gains from trade will be identical across models that generate the same trade elasticity - extends to a dynamic environment.

\subsection{No Exporter Growth (Sunk-Cost Model)}

The slow export growth of producers is important for the welfare and trade response to a change in trade barriers. To show this, we set $\xi_{L}=\xi_{H}=\xi$ so that the intensity with which a producer exports does not change over its time in the export market. This is a variation of the model studied by Alessandria and Choi (2011). In terms of export intensity, new exporters look just like old exporters in this model. This version of the model is recalibrated to match similar features of exporting and trade. Table 1 summarizes the parameters, while Table 2 summarizes the effect of abstracting from export intensity dynamics on aggregate outcomes. Figures 5 to 7 plot the transition to the new steady-state.

The sunk-cost model generates a smaller long-run expansion of trade than in the benchmark model. The trade elasticity is about 63 percent of the benchmark model (7.2 vs 11.5). The trade transition, though, is relatively faster, as the discounted trade elasticity is about 68 percent of the benchmark model's (6.9 vs 10.15). The sunk-cost model generates a larger change in steady-state consumption than in our benchmark model (1.98 vs 0.42$)$ but a smaller 
welfare gain (4.75 percent vs 6.30$)$.

The benchmark model generates a larger welfare gain than the sunk-cost model because overshooting is stronger even as trade grows more slowly. In terms of consumption, both models generate similar dynamics in the first two to three years. However, the sunk-cost model peaks four years earlier and at a level below the benchmark model. The gap that opens between the models closes only slowly. The more-delayed and larger dynamics of consumption in the benchmark model reflect the dynamics of new exporter growth. In the benchmark model, more time and resources are used to build the stock of exporters initially, so it takes longer to benefit from this entry since exporters take time to become more efficient. The stronger long-run effect on consumption in the sunk-cost model arises because there is less substitution between trade and variety creation than in our benchmark model. Indeed, in the long run, the stock of domestic producers falls by only 4.8 percent in the sunk-cost model compared to 13.1 in the benchmark model.

\subsection{No Export Decision (No-Cost Model)}

To further explore how the micro details of exporting matter for aggregate welfare, we now consider a version of the model in which all establishments export from birth (i.e., there are no fixed export costs, $f_{H}=f_{L}=0$ ) with the same iceberg cost (i.e., $\xi_{L}=\xi_{H}$ ). This is a variation of the Krugman (1980) model. Without some modification, the trade elasticity is constant in this model. To generate a gradual increase in the trade elasticity, as in our benchmark model, it is necessary to introduce an adjustment friction to either the final goods aggregator or the trade cost. We introduce an adjustment cost into the aggregation of intermediates by final goods producers. ${ }^{9}, 10$ Specifically, the aggregator is modified to include

\footnotetext{
${ }^{9}$ One can think of this specification as representing the challenges that firms face in adjusting their inputs in the short run. This adjustment cost shares some similarities with that studied by Engel and Wang (2011).

${ }^{10}$ Alternatively, we could have generated slow trade growth by making the tariff fall gradually or allowing the iceberg cost to depend on the change in the import share (i.e., $\xi_{t}=\xi e^{-v \ln \lambda_{t} / \lambda_{t-1}}$ ). Both of these approaches yield similar findings in that they reduce consumption along the transition, but the trade elasticity would be constant in these cases.
} 
a time-varying weight on imported goods

$$
\begin{aligned}
D_{t} & =\left[\int_{z} y_{H, t}^{d}(z)^{\frac{\theta-1}{\theta}} \varphi_{t}(z) d z+g_{t} \int_{z} y_{F, t}^{d}(z)^{\frac{\theta-1}{\theta}} \varphi_{t}^{*}(z) d z\right]^{\frac{\theta}{\theta-1}} \\
g_{t} & =g_{t-1}^{\rho_{g}}\left[\left(\frac{\lambda_{t}}{\lambda_{t-1}}\right)^{v}\right]^{1-\rho_{g}}, g_{-1}=1
\end{aligned}
$$

where $\lambda_{t}$ is the home intermediate goods' expenditure share. With $v>0$, the term $g_{t}$ implies that an increase in the import share will lower the weight on imports in the aggregator. ${ }^{11}$ This demand shifter is assumed to depend on aggregate imports and is external to the final goods producer. It can be interpreted as a cost of adjusting inputs. It affects only the transition and not the steady-state.

The parameters of the final goods aggregator, $v$ and $\rho_{g}$, are set to minimize the gap between the trade elasticity in the benchmark model and in this model, which is called the No-cost model:

$$
\left\{v^{*}, \rho_{g}^{*}\right\}=\arg \min _{\left\{v, \rho_{g}\right\}}\left\{\sum_{t=0}^{\infty}\left[\beta^{t}\left(\varepsilon_{\text {Benchmark }, t}-\varepsilon_{\text {Nocost }, t}\right)\right]^{2}\right\}
$$

This gives $v=1.89$ and $\rho_{g}=0.25$. Figure 5 plots the trade elasticity in the model with and without the adjustment cost slowing down trade (No-cost No sluggish).

For the No-cost model to match the long-run trade elasticity in the benchmark model, the elasticity of substitution, $\theta$, is increased from 5 to 12.54. This lowers markups from 25 percent to about eight percent, which has the effect of changing the labor share of income, the ratio of gross-output to value added, and the ratio of trade to value added. To maintain the same macro targets for the ratio of trade to shipments, labor share, and materials usage, we must adjust $\alpha_{x}, \alpha$, and $\xi$ accordingly. The capital share is roughly doubled from 14 percent to 28 percent; the material usage is lowered from 80 percent to 70 percent; and the iceberg cost is lowered to 1.11. The parameters are reported in Table 1. The column No-cost in Table 2 summarizes the aggregate effects of the cut in tariffs considered in this alternative model, and Figures 5 to 7 plot some aspects of the transition.

\footnotetext{
${ }^{11}$ The term $g_{t}$ can be thought of as a wedge that accounts for the changes in trade that cannot be explained by relative prices. Recent work by Levchenko, Lewis, and Tesar (2010) and Alessandria, Kaboski, and Midrigan (2013) show that there are substantial cyclical fluctuations in this wedge.
} 
The key focus is on the change in welfare. The gains are almost four percentage points larger in the benchmark model (6.3 vs 2.3), even though the steady-state change in consumption is about 3.5 percentage points lower in the benchmark model (0.42 vs 3.93). This large gap in welfare occurs because consumption in the benchmark model overshoots the new steady-state, while in the No-cost model, consumption grows quite gradually. The gap in consumption between the models is as large as 7.8 percentage points five years after the policy change. The gradual consumption growth in the No-cost model occurs because the economy decumulates establishments only temporarily, with much smaller magnitudes, and capital and trade grow gradually due to the adjustment cost in the use of inputs in the production of final goods. ${ }^{12}$ This suggests that focusing on the relationship between the trade elasticity and welfare is not sufficient to estimate the gains from trade. Instead, one must also consider how the scale of the economy is changing.

\section{Conclusions}

We develop a model consistent with the evidence that trade is sluggish at the producer and aggregate levels. In our theory, it takes time and resources to lower the marginal cost of exporting. This implies that the distribution of iceberg costs is endogenous and reflects the investment decisions of producers. We estimate the effect of a cut in tariffs on trade and the gains from trade in a general equilibrium variation of our theory. Surprisingly, although we find that trade grows sluggishly, we also find that the benefits of a cut in tariffs are more immediate. Including these transition periods increases by more than 15 times the welfare gains from a change in trade policy relative to the change in steady-state allocations. Models without this dynamic export decision underestimate the gains from removing trade barriers, particularly when constrained to also match the sluggishness in trade expansion.

We develop a model of producer-level export growth in which the technology for exporting is endogenous. This is a more general version of the standard fixed-variable cost trade-off emphasized in the literature. We find that the estimated technology for exporting is risky

\footnotetext{
${ }^{12}$ Eliminating the adjustment cost in inputs would speed up the transition and increase the welfare gains in the No-Cost model to 3.5 percent. However, the path of aggregate dynamics would remain quite different from that in our benchmark model.
} 
and that time in the export market is important to becoming a successful exporter. New exporters are willing to incur substantial losses for a number of years as they build their foreign sales. This suggests smaller up-front costs and larger continuation costs compared to those found in other studies; it also suggests that the benefits from entering the export market accrue more gradually. Other sources of producer-level export growth, such as building distribution networks or brand recognition, are likely to also be important. However, we suspect that these alternative explanations for sluggishness will generate similar micro and macro dynamics since they also increase the costs of entry and push the profits from exporting into the future, making exporters reluctant to exit the export market.

Finally, in our analysis, the gap between the short-run and long-run aggregate trade elasticity is disciplined by evidence on producer-level export dynamics. The dynamics of the aggregate trade elasticity following a trade reform are also likely to depend on general equilibrium considerations of the infrastructure for trade, such as customs, ports, pipelines, and railroads, which must be expanded to accommodate the increased flow of goods. Accumulating these forms of trade-specific physical capital, as opposed to the producer-specific exporter capital emphasized here, is likely to generate familiar neoclassical transition dynamics.

\section{References}

Alessandria, G., and H. Choi (2007): "Do Sunk Costs of Exporting Matter for Net Export Dynamics?," Quarterly Journal of Economics, 122(1), 289-336.

(2011): "Establishment Heterogeneity, Exporter Dynamics, and the Effects of Trade Liberalization," Working Papers 11-19, Federal Reserve Bank of Philadelphia.

Alessandria, G., J. Kaboski, and V. Midrigan (2013): "Trade Wedges, Inventories, and International Business Cycles," Journal of Monetary Economics, 60(1), 1-20.

Alessandria, G., S. Pratap, and V. Yue (2013): "Export Dynamics in Large Devaluations," Hong Kong Institute for Monetary Research Working Paper 062013.

Arkolakis, C., A. Costinot, and A. Rodríguez-Clare (2012): "New Trade Models, Same Old Gains?," American Economic Review, 102(1), 94-03.

Baldwin, R. E. (1992): "Measurable Dynamic Gains from Trade," Journal of Political Economy, 100(1), 162-174.

Baldwin, R. E., and P. Krugman (1989): "Persistent Trade Effects of Large Exchange Rate Shocks," Quarterly Journal of Economics, 104(4), 635-654. 
Bernard, A. B., and J. B. Jensen (1999): "Exceptional Exporter Performance: Cause, Effect, or Both?," Journal of International of Economics, 47(1), 1-25.

Burstein, A., And M. J. Melitz (2011): "Trade Liberalization and Firm Dynamics," NBER Working Paper 16960, National Bureau of Economic Research.

Chaney, T. (2005): "Productivity Overshooting: The Dynamic Impact of Trade Opening with Heterogeneous Firms," mimeo, University of Chicago.

Das, S., M. J. Roberts, and J. R. Tybout (2007): "Market Entry Costs, Producer Heterogeneity, and Export Dynamics," Econometrica, 75(3), 837-873.

Davis, S. J., J. C. Haltiwanger, and S. Schuh (1998): Job Creation and Destruction. MIT Press Books.

Dixit, A. (1989): "Hysteresis, Import Penetration, and Exchange Rate Pass-through," Quarterly Journal of Economics, 104(2), 205-228.

Drozd, L. A., And J. B. Nosal (2012): "Understanding International Prices: Customers as Capital," American Economic Review, 102(1), 364-395.

Dunne, T., M. J. Roberts, and L. Samuelson (1989): "The Growth and Failure of U.S. Manufacturing Plants," Quarterly Journal of Economics, 104(4), 671-698.

Eaton, J., M. Eslava, C. J. Krizan, M. Kugler, and J. Tybout (2009): "A Search and Learning Model of Export Dynamics," mimeo.

Engel, C., And J. Wang (2011): "International Trade in Durable Goods: Understanding Volatility, Cyclicality, and Elasticities," Journal of International Economics, 83(1), 37-52.

Gallaway, M. P., C. A. McDaniel, and S. A. Rivera (2003): "Short-Run and LongRun Industry-Level Estimates of U.S. Armington Elasticities," North American Journal of Economics and Finance, 14(1), 49-68.

Hooper, P., K. Johnson, and J. Marquez (2000): "Trade Elasticities for the G-7 Countries," Princeton Studies in International Economics, 87.

Krugman, P. (1980): "Scale Economies, Product Differentiation, and the Pattern of Trade," American Economic Review, 70(5), 950-959.

Levchenko, A. A., L. T. Lewis, and L. L. Tesar (2010): "The Collapse of International Trade During the 2008-2009 Crisis: In Search of the Smoking Gun," IMF Economic Review, 58(2), 214-53.

Melitz, M. J. (2003): "The Impact of Trade on Intra-Industry Reallocations and Aggregate Industry Productivity," Econometrica, 71(6), 1695-1725.

Obstanld, M., and K. Rogoff (2005): "The Unsustainable U.S. Current Account Position Revisited," Proceedings, Federal Reserve Bank of San Francisco. 
Ramanarayanan, A. (2007): "International Trade Dynamics with Intermediate Inputs," 2007 Meeting Papers 722, Society for Economic Dynamics.

Rho, Y.-W., And J. Rodrigue (2013): "Firm-Level Investment and Export Dynamics," mimeo, Vanderbilt University.

Ruhl, K. J. (2008): "The International Elasticity Puzzle," mimeo, NYU Stern School of Business.

Ruhl, K. J., And J. L. Willis (2008): "New Exporter Dynamics," mimeo, NYU Stern School of Business. 
Figure 1A: Export Intensity of Colombian Exporters

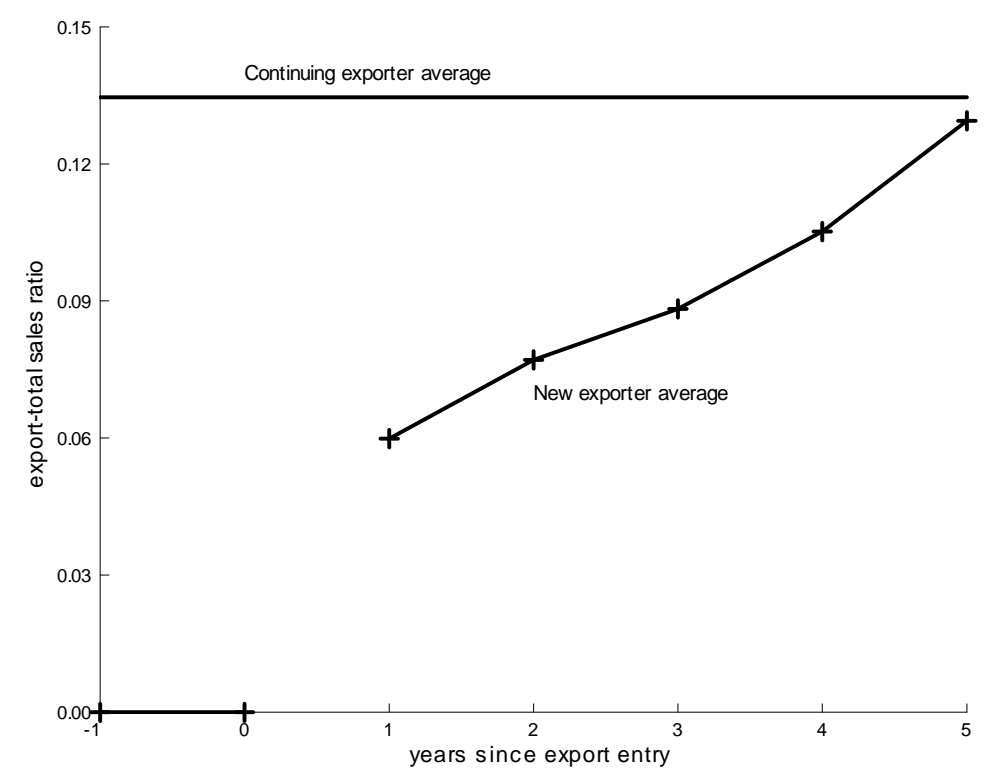

Figure 1B: Colombian Exporter Continuation Rate

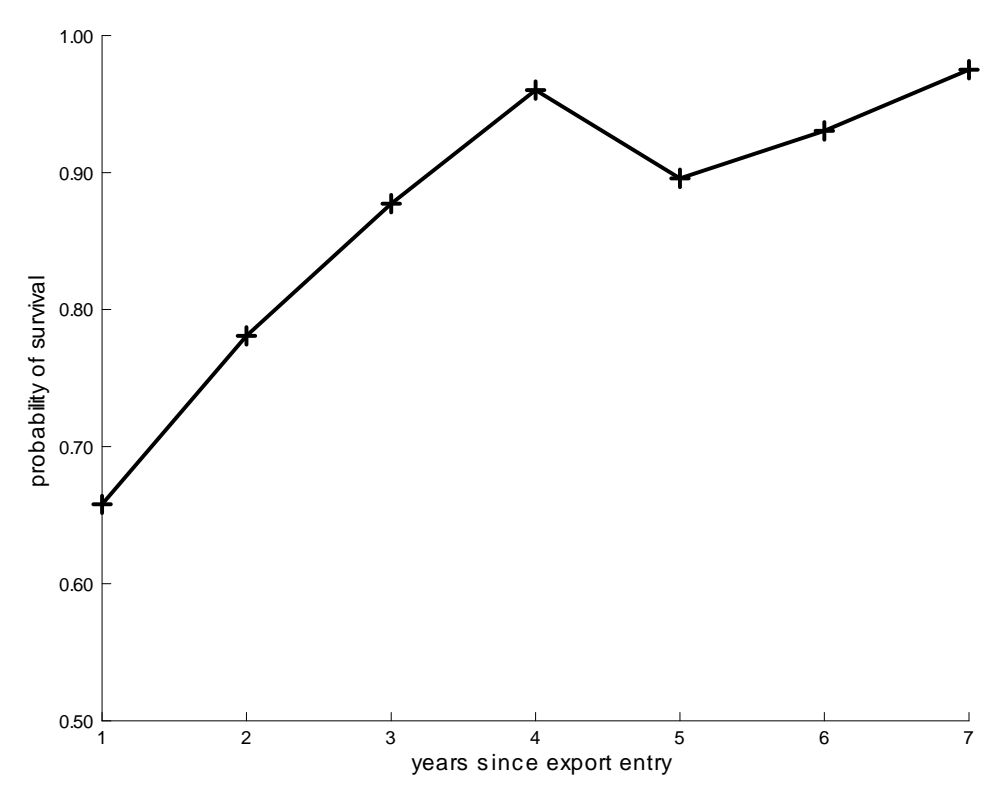




\section{Figure 2: Exporter Dynamics in Stationary Steady State}

A. Exporter Intensity and Duration

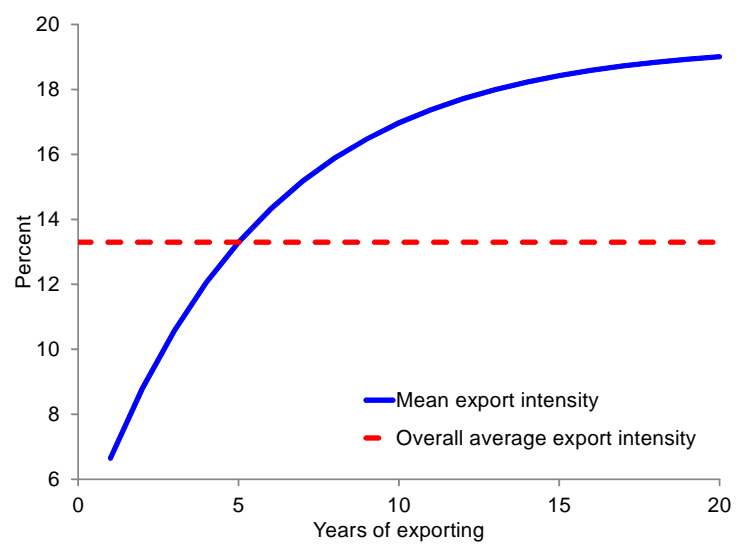

C. Profits (Net/Entry Costs) of Marginal Starters

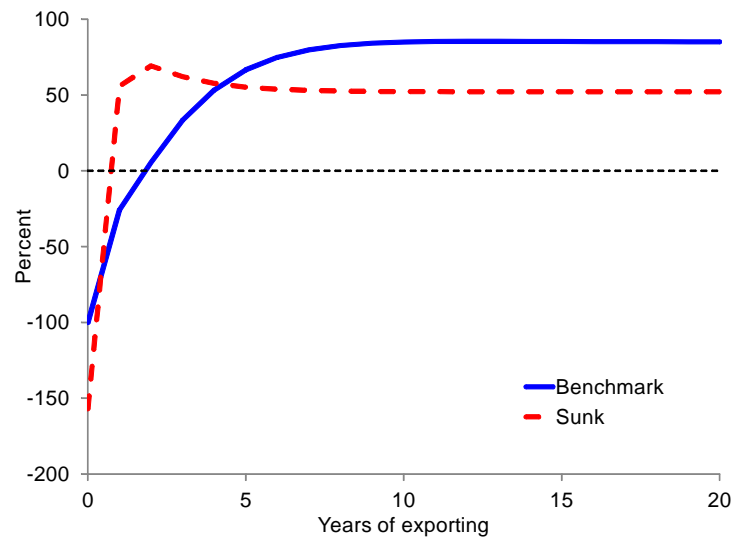

B. Continuation Rate (One Year) and Duration

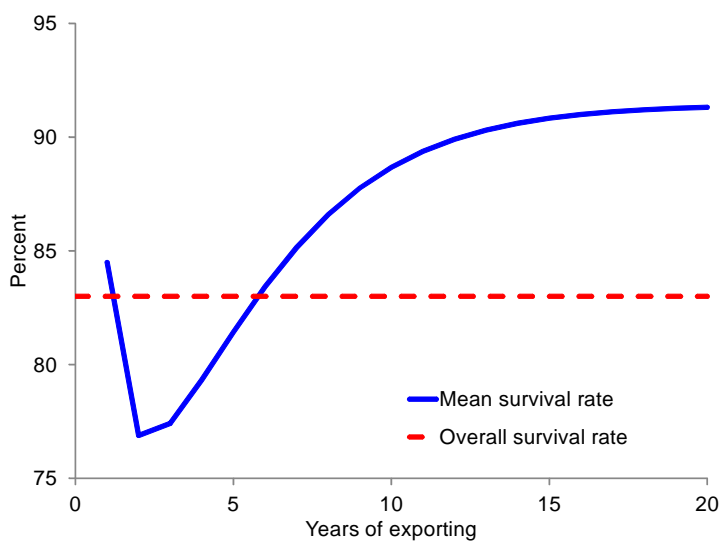

D. Cumulative Profits of Marginal Starters

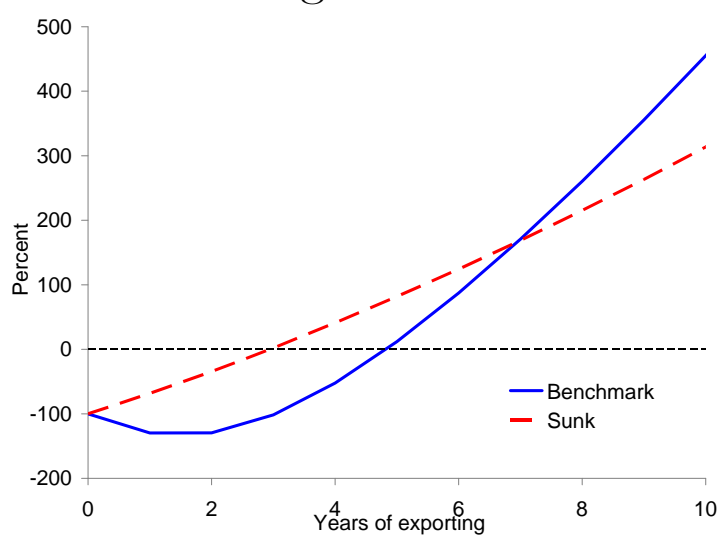


Figure 3: Benchmark Model Elimination of 10 Percent Tariff

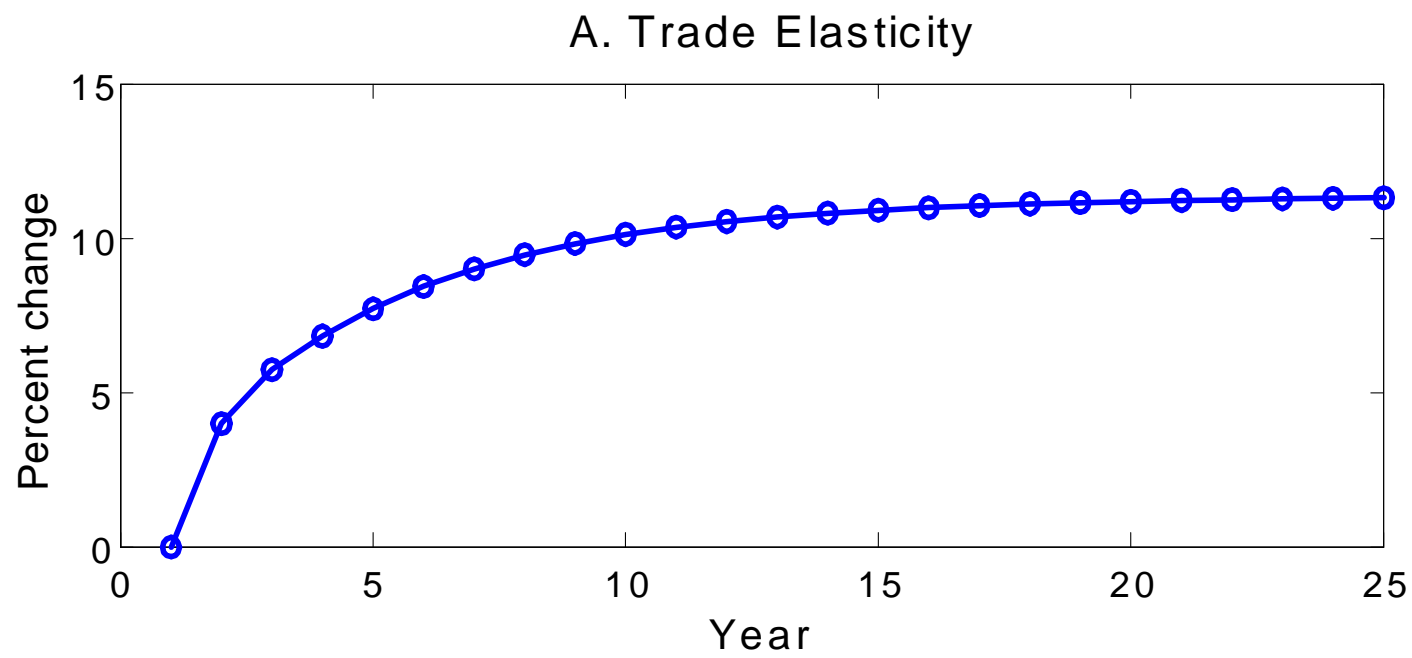

B. Consumption, W age, Output, and Production Labor

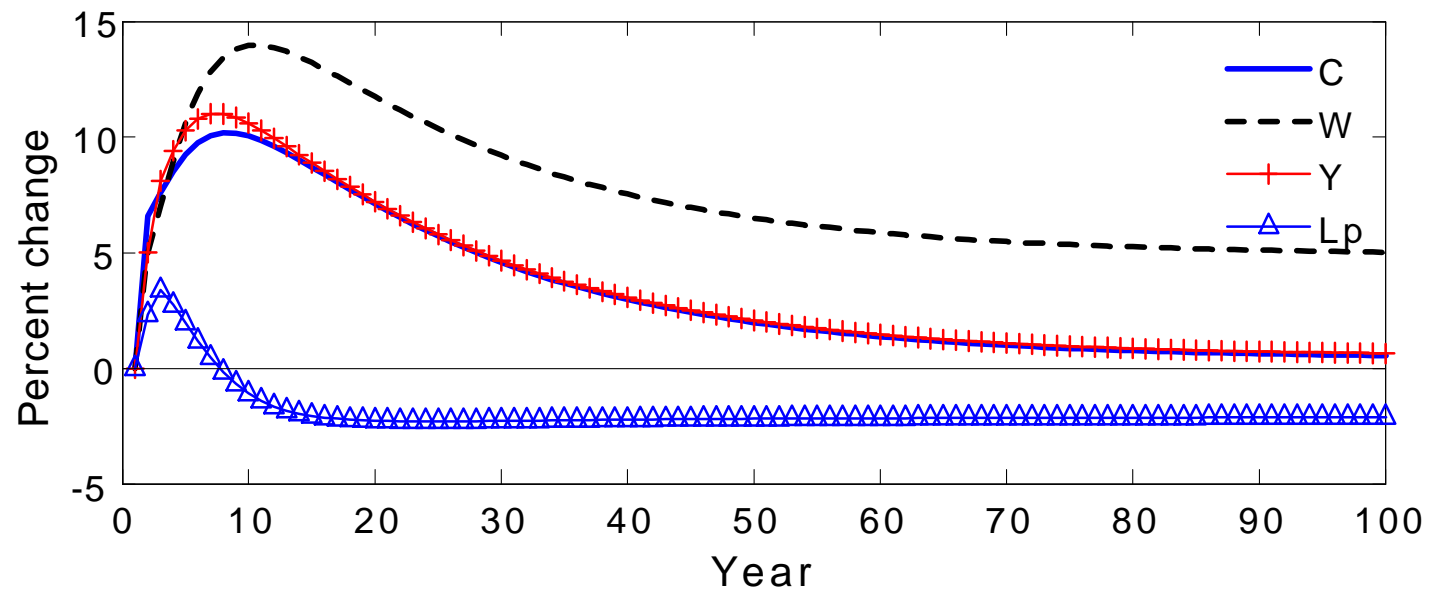

C. Investment (X), Entry (NE), and Establishments (N)

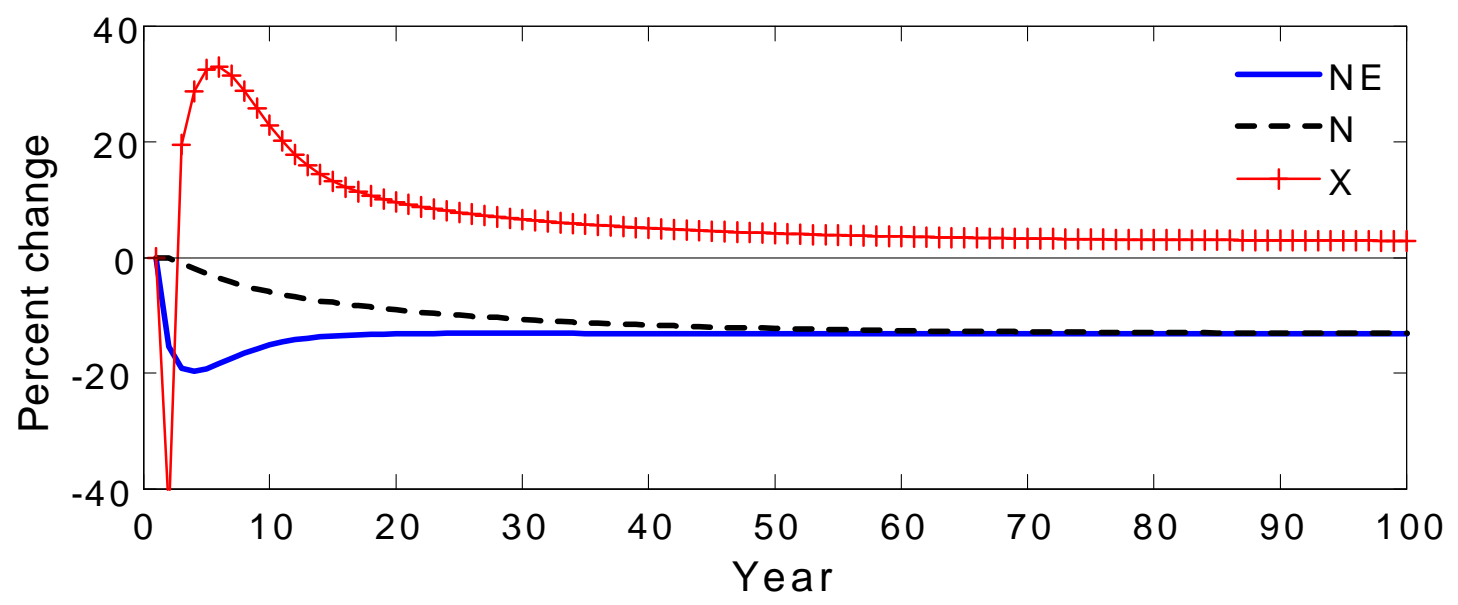


Figure 4: Role of Entry Adjustment on Trade and Consumption
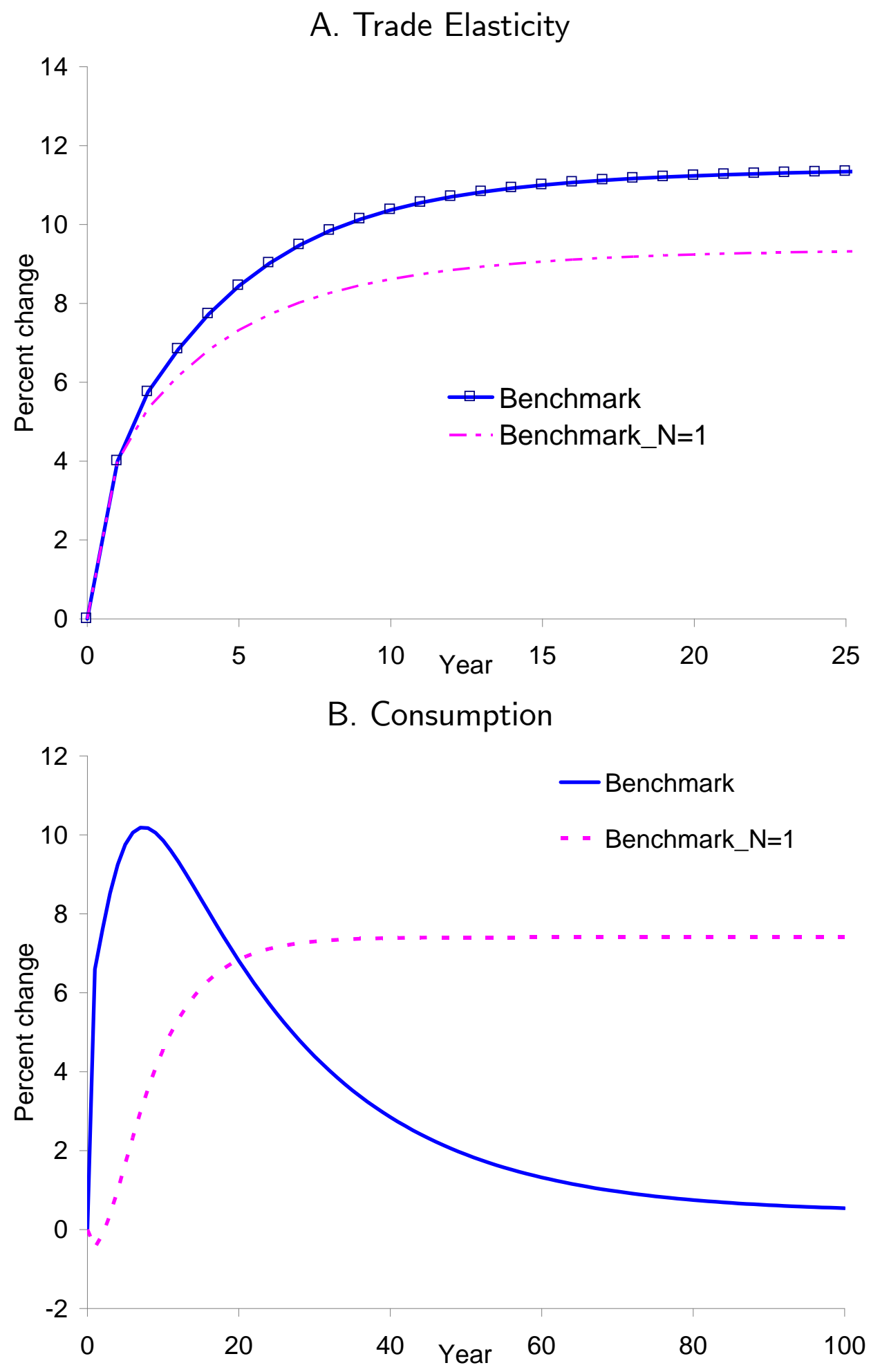
Figure 5: Comparison of Trade Dynamics

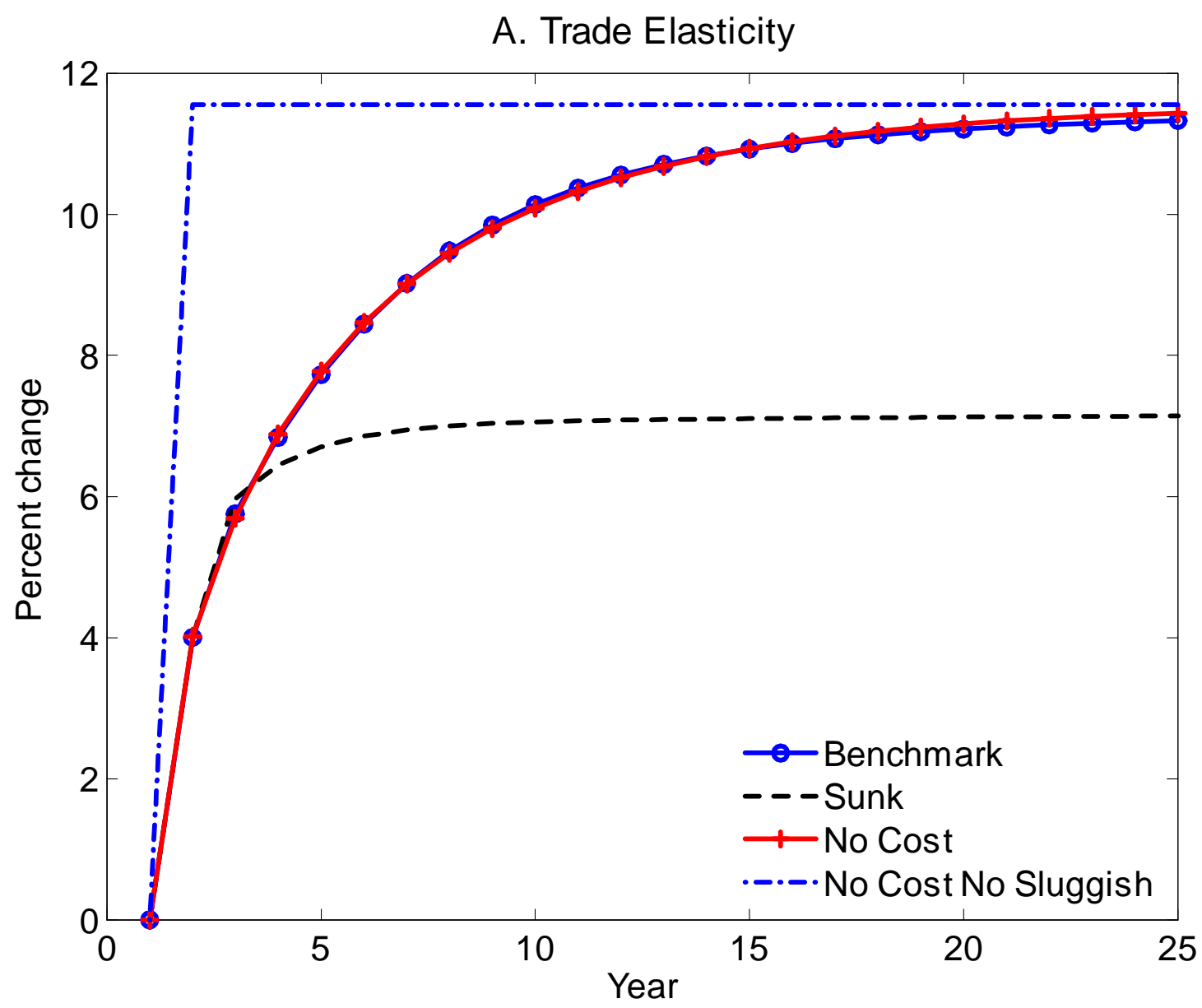


Figure 6: Comparison of Consumption, Wage, and Output Dynamics
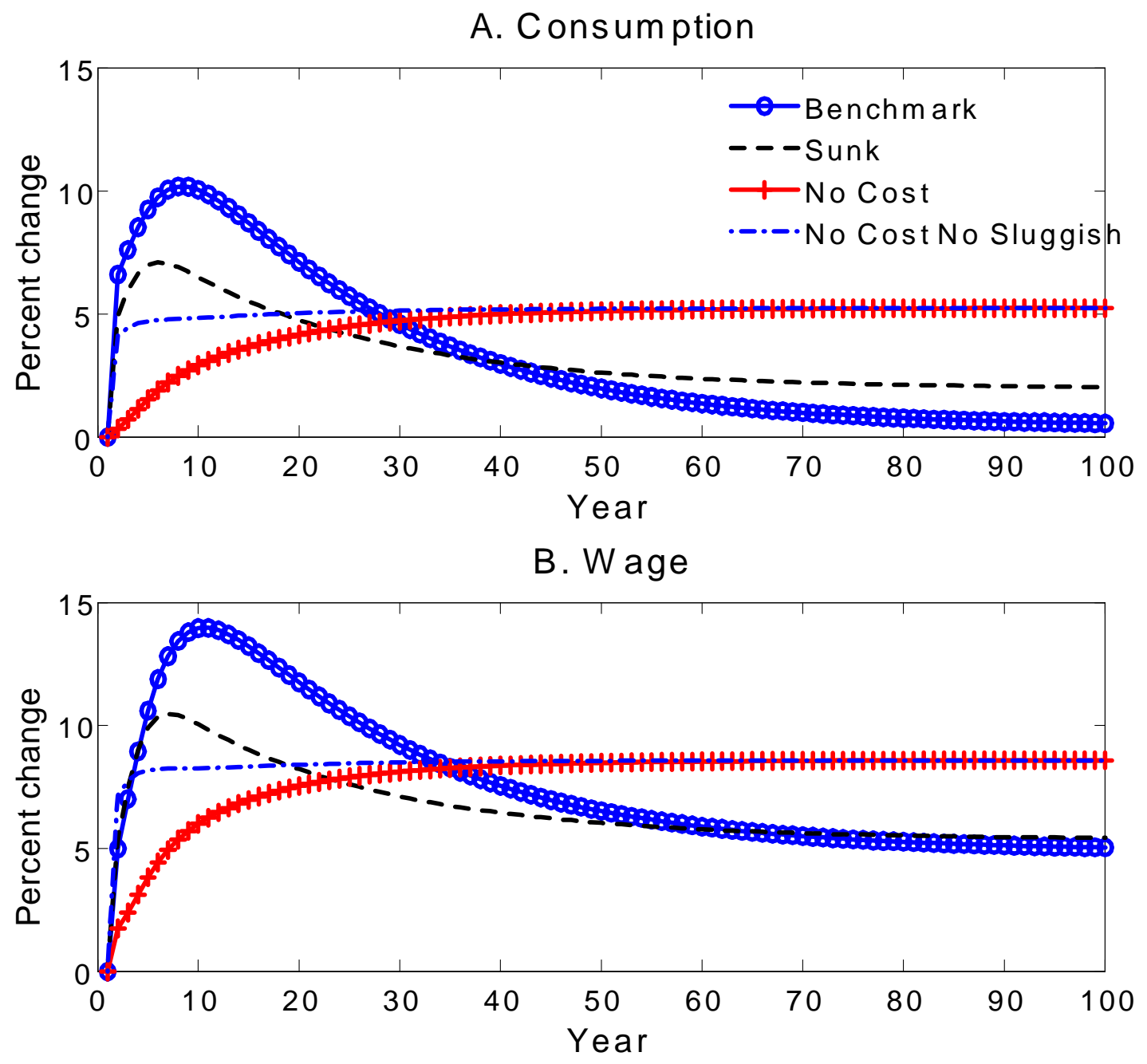

C. Output

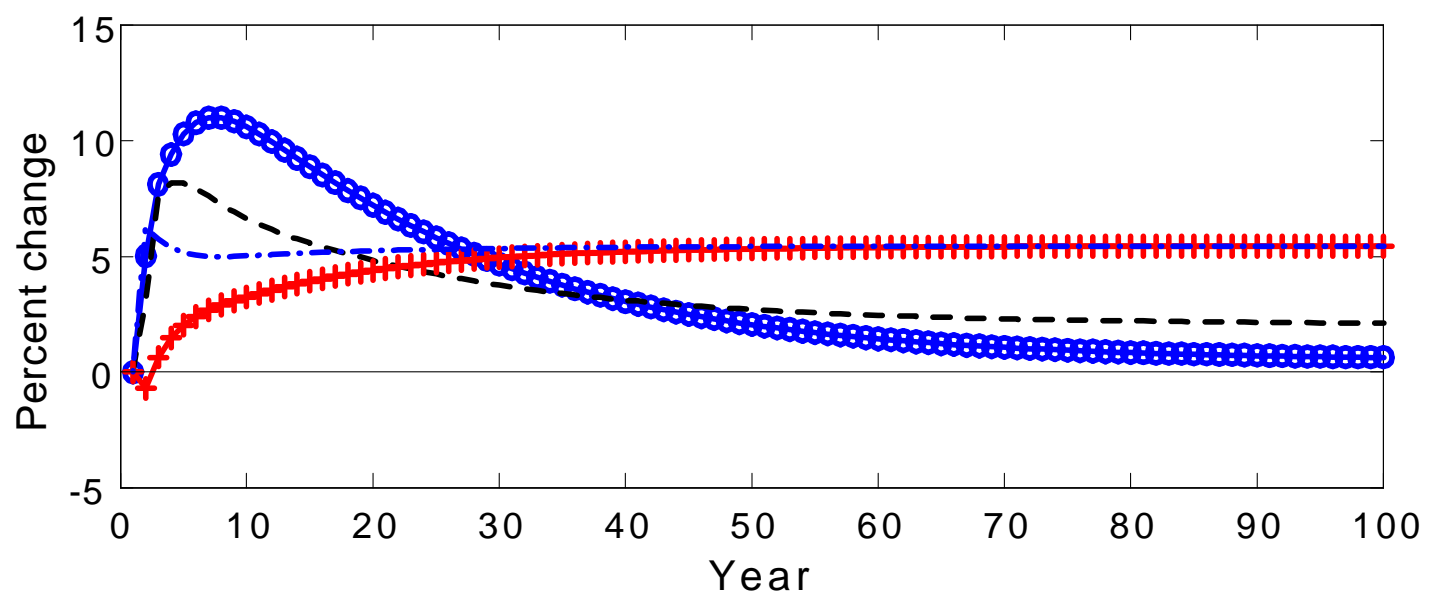


Figure 7: Comparison of Investment, Entry, and Labor Dynamics
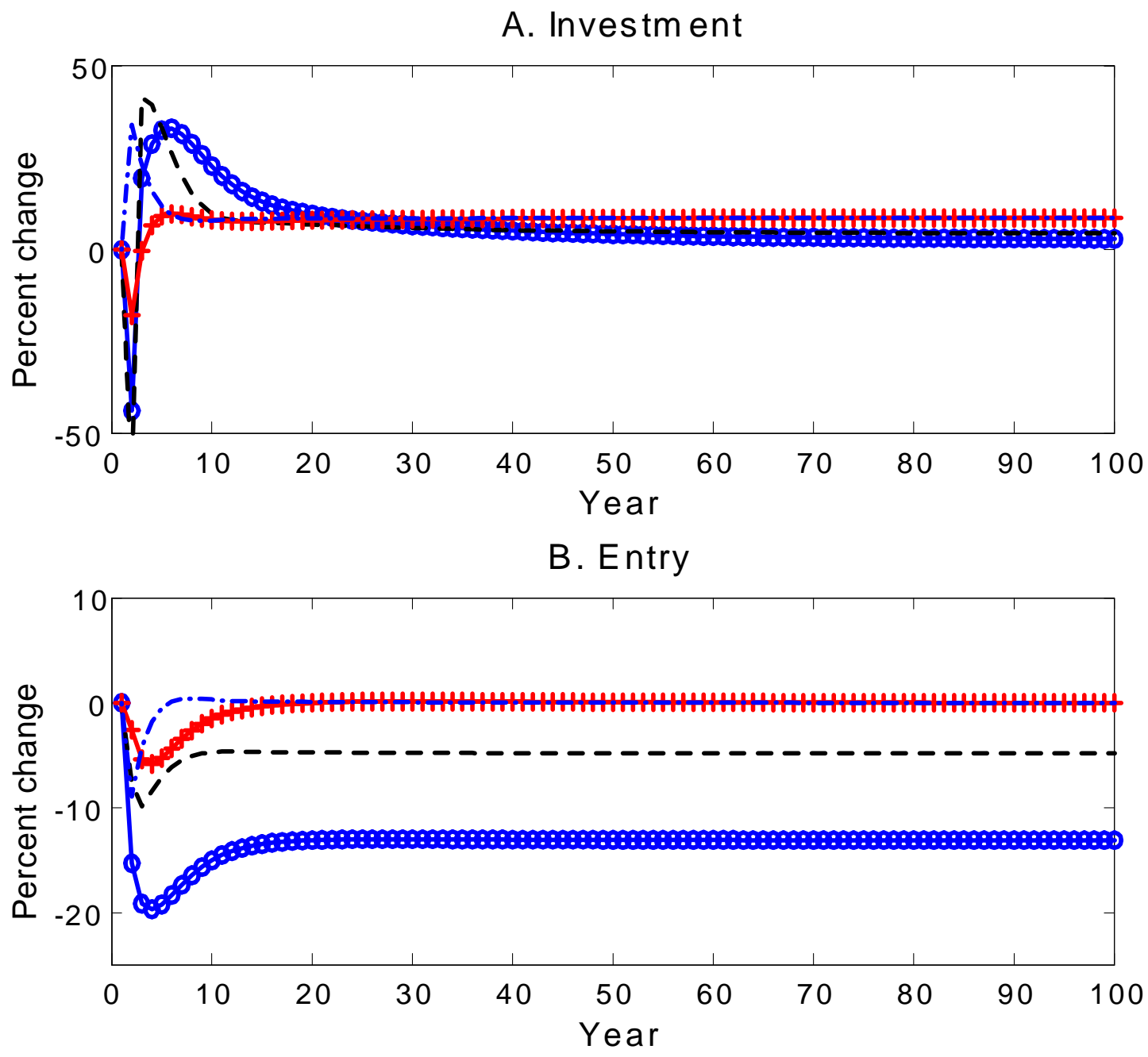

C. Labor in Production

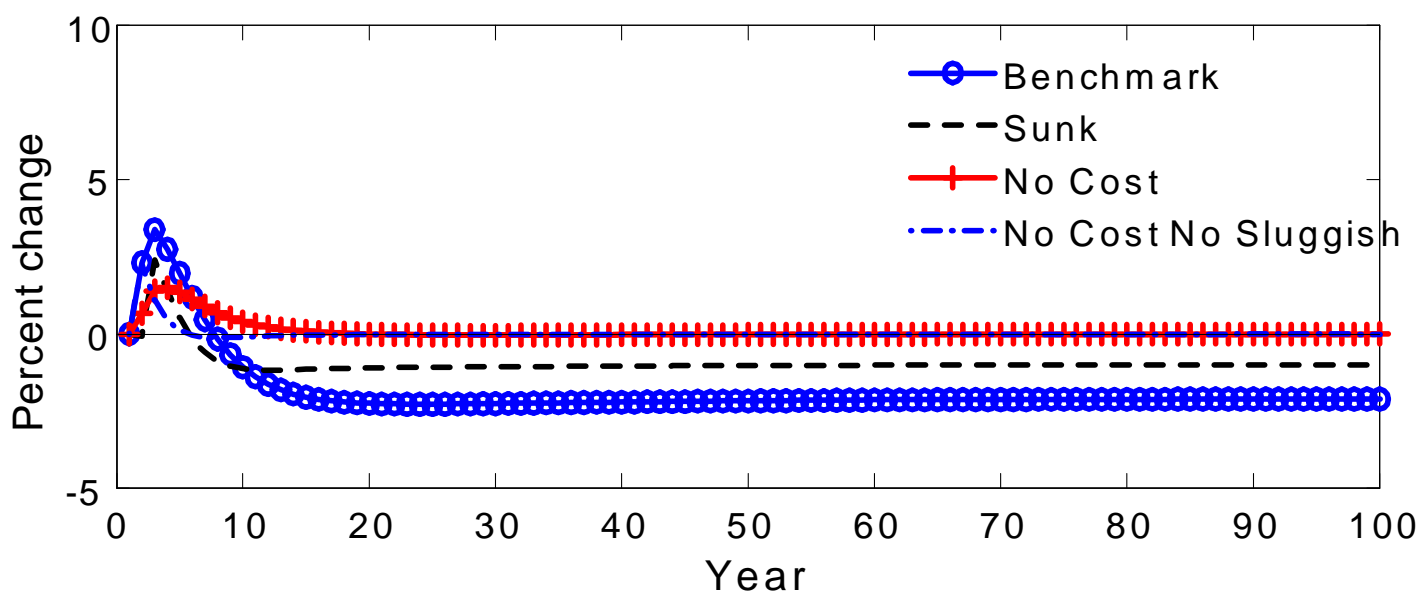




\title{
Analytical Appendix to "Trade Adjustment Dynamics and the Welfare Gains from Trade" (Not for publication)
}

\author{
George Alessandria \\ Federal Reserve Bank of Philadelphia \\ Horag Choi \\ Monash University \\ Kim Ruhl \\ NYU Stern School of Business
}

Draft: February 2014

First Draft: December 2013

\section{A Analytical Solutions to a Model with New-Exporter Dynamics}

In this appendix, we analytically examine the role of exporter dynamics for the long-run distortions from tariffs. We show that with new-exporter dynamics that the following are true:

1. The trade elasticity is higher.

2. The steady-state change in consumption is smaller for a given trade growth.

3. The stock of establishments increases with tariffs, and more so as we increase the discount factor and disadvantage of new exporters.

To make these points most clearly, we keep the main elements related to new-exporter dynamics and eliminate other elements. Specifically, as in the benchmark model, new exporters have a disadvantage in that they face a relatively high marginal trade $\operatorname{cost} \xi_{H}>\xi_{L}$ when they start exporting. We eliminate capital accumulation, input-output structure, and general transition probability for iceberg costs. Notes with these extensions are available from the authors.

We make the following modification to the benchmark model to obtain the analytical solutions. First, in each period, producers draw their elasticity-adjusted productivity $a=e^{(\theta-1) z}$ from a Pareto distribution with $a>1$, and the slope parameter of $\eta>11$ The pdf of the distribution is given by $\phi(a)=\eta a^{-(\eta+1)}$. Second, the exogenous shutdown probability is constant with $n_{d}=1-n_{s}$. Third, producers face the fixed costs in exporting $f_{X}=f_{L}=f_{H}$ measured in labor units. See Alessandria and Choi (2011) for results when there is a sunk export cost $\left(f_{H} \geq f_{L}\right)$. The payment should be made when they export. Fourth, there are fixed costs in production $f_{P}$ measured in labor units. If a producer does not pay the fixed cost in production, it becomes dormant in the current period. For notational simplicity, we replace $1+\xi$ with $\xi$, and $1+\tau$ with $\tau$. To obtain clear-cut solutions, we assume that the tariff rate is also an iceberg cost. As in the benchmark model, we assume that $\rho=\rho_{\xi}\left(\xi_{H} \mid \xi_{H}\right)=\rho_{\xi}\left(\xi_{L} \mid \xi_{L}\right)>1 /\left.2\right|^{2}$ For notational convenience, we focus on the

\footnotetext{
*Corresponding author: george.alessandria@gmail.com, Ten Independence Mall, Philadelphia, PA 19106.

${ }^{1}$ With the elasticity-adjusted productivity $a$, the relative size of a producer is proportional to $a$.

${ }^{2}$ We assume that $\rho_{\xi}\left(\xi_{L} \mid \xi_{L}\right)>\rho_{\xi}\left(\xi_{L} \mid \xi_{H}\right)$ by setting $\rho>1 / 2$.
} 
symmetric steady state. We will skip the agent's problems, as they are identical to those in the benchmark model.

\section{A.1 Consumers}

The first-order conditions from the consumer's problem in the steady state give the budget constraint,

(1) $\quad C=W L+\Pi+T$.

\section{A.2 Final Good Producers}

The final good producers' problem yields the demand for goods,

(2) $y_{H}^{d}(a, \xi)=\left[P_{H, t}(a, \xi)\right]^{-\theta} C$,

(3) $y_{F}^{d}(a, \xi)=\left[P_{F}(a, \xi)\right]^{-\theta} C$,

and the normalized final good's price index, $P=1$,

(4) $1=\sum_{\xi \in\left\{\xi_{L}, \xi_{H}, \infty\right\}} \int\left[P_{H, t}(a, \xi)^{1-\theta} \varphi_{H, t}(a, \xi)+\left[P_{F, t}(a, \xi)\right]^{1-\theta} \varphi_{F, t}(a, \xi)\right] d a$.

Note that we replace the productivity $z$ with its level $a$.

\section{A.3 Intermediate Good Producers}

The first-order conditions give the pricing rule

(6) $P_{H}^{*}(a, \xi)=\tau \xi\left(\frac{\theta W}{\theta-1}\right) a^{\frac{1}{1-\theta}}$,

and the demands for inputs

(7) $\quad l(z, \xi)=a^{\frac{1}{1-\theta}} y(a, \xi)$.

The total output of a producer with $(a, \xi)$ is given by

(8) $y(a, \xi)=y_{H}^{d}(a, \xi)+\tau \xi y_{H}^{* d}(a, \xi)=\left(\frac{\theta W}{\theta-1}\right)^{-\theta}\left(1+\tau^{1-\theta} \xi^{1-\theta}\right) a^{\frac{\theta}{\theta-1}} C$.

Using (8), we can rewrite the demands for inputs as

(9) $l(a, \xi)=\left(1+\tau^{1-\theta} \xi^{1-\theta}\right)\left(\frac{\theta W}{\theta-1}\right)^{-\theta} a C$.

The operating profit of a producer with $(a, \xi)$ is given by

$$
\begin{aligned}
\Pi(a, \xi) & =P_{H}(a, \xi) y_{H}(a, \xi)+P_{H}^{*}(a, \xi) y_{H}^{* d}(a, \xi)-W l(a, \xi) \\
& =P_{H}(a, \xi) y(a, \xi)-\left(\frac{\theta-1}{\theta}\right)\left(1+\tau^{1-\theta} \xi^{1-\theta}\right)\left(\frac{\theta W}{\theta-1}\right)^{1-\theta} a C \\
& =\left(\frac{1}{\theta}\right)\left(1+\tau^{1-\theta} \xi^{1-\theta}\right)\left(\frac{\theta W}{\theta-1}\right)^{1-\theta} a C
\end{aligned}
$$


Marginal Productivity: Let $\Pi_{0}=\left(\frac{1}{\theta}\right)\left(\frac{\theta W}{\theta-1}\right)^{1-\theta} C$, the operating profit of a non-exporter with $a=$ 1. The marginal active producer's productivity $a_{P}$ satisfies

(11) $W f_{P}=\Pi\left(a_{P}, \infty\right)=\Pi_{0} a_{P}$.

Here, we assume that $f_{P}$ is sufficiently high so that $a_{P}>1$, and $f_{X}$ is relatively high so that the marginal active producer with $a_{P}$ does not export. The value of an active producer with $(a, \xi)$ is given by

(12) $v(a, \xi)=\Pi_{0}\left(1+\tau^{1-\theta} \xi^{1-\theta}\right) a-W f_{P}-W f+n_{s} \beta E V(\xi)$

where $E V(\xi)$ is the expected value of the producer with $\xi$ last period, and $f$ is the optimal choice of the producer with $\xi$. Specifically,

$$
\begin{aligned}
E V(\infty)= & \int_{1}^{a_{H}} v(a, \infty) \phi(a) d a+\int_{a_{H}}^{\infty} v\left(a, \xi_{H}\right) \phi(a) d a \\
E V\left(\xi_{H}\right)= & \rho\left[\int_{1}^{a_{H}} v(a, \infty) \phi(a) d a+\int_{a_{H}}^{\infty} v\left(a, \xi_{H}\right) \phi(a) d a\right] \\
& +(1-\rho)\left[\int_{1}^{a_{L}} v(a, \infty) \phi(a) d a+\int_{a_{L}}^{\infty} v\left(a, \xi_{L}\right) \phi(a) d a\right] \\
E V\left(\xi_{L}\right)= & (1-\rho)\left[\int_{1}^{a_{H}} v(a, \infty) \phi(a) d a+\int_{a_{H}}^{\infty} v\left(a, \xi_{H}\right) \phi(a) d a\right] \\
& +\rho\left[\int_{1}^{a_{L}} v(a, \infty) \phi(a) d a+\int_{a_{L}}^{\infty} v\left(a, \xi_{L}\right) \phi(a) d a\right]
\end{aligned}
$$

where the marginal exporters' productivity $a_{H}$ and $a_{L}$ satisfy

(16) $v\left(a_{H}, \xi_{H}\right)=v\left(a_{H}, \infty\right)$,

(17) $v\left(a_{L}, \xi_{L}\right)=v\left(a_{L}, \infty\right)$.

Using (12), we can rewrite the conditions as

$$
\begin{aligned}
W f_{X} & =\Pi_{0} \tau^{1-\theta} \xi_{H}^{1-\theta} a_{H}+n_{s} \beta\left[E V\left(\xi_{H}\right)-E V(\infty)\right] \\
W f_{X} & =\Pi_{0} \tau^{1-\theta} \xi_{L}^{1-\theta} a_{L}+n_{s} \beta\left[E V\left(\xi_{L}\right)-E V(\infty)\right]
\end{aligned}
$$

Let

$$
\begin{aligned}
\Psi_{j} & =\int_{a_{j}}^{\infty} a \phi(a) d a=\left(\frac{\eta}{\eta-1}\right) a_{j}^{1-\eta} \\
n_{j} & =\int_{a_{j}}^{\infty} \phi(a) d a=a_{j}^{-\eta}
\end{aligned}
$$

where $j \in\{P, H, L\}$. Then, we can rewrite the expected value of a non-exporter as

$$
\begin{aligned}
E V(\infty)= & \Pi_{0}\left(\Psi_{P}+\tau^{1-\theta} \xi_{H}^{1-\theta} \Psi_{H}\right)-n_{P} W f_{P}-n_{H} W f_{X} \\
& +n_{s} \beta\left[n_{H} E V\left(\xi_{H}\right)+\left(1-n_{H}\right) E V(\infty)\right] \\
= & \left(\frac{\Pi_{0}}{\eta}\right)\left(\Psi_{P}+\tau^{1-\theta} \xi_{H}^{1-\theta} \Psi_{H}\right)+n_{s} \beta E V(\infty) \\
= & \left(\frac{1}{1-n_{s} \beta}\right)\left(\frac{\Pi_{0}}{\eta}\right)\left(\Psi_{P}+\tau^{1-\theta} \xi_{H}^{1-\theta} \Psi_{H}\right) .
\end{aligned}
$$


The entry condition is given by

$$
\begin{aligned}
W f_{E} & =\beta E V(\infty) \\
& =\left(\frac{\beta}{1-n_{s} \beta}\right)\left(\frac{\Pi_{0}}{\eta}\right)\left(\Psi_{P}+\tau^{1-\theta} \xi_{H}^{1-\theta} \Psi_{H}\right)
\end{aligned}
$$

The expected values of an exporter with $\xi=\xi_{H}$ can be rewritten as

$$
\begin{aligned}
E V\left(\xi_{H}\right)= & \Pi_{0}\left[\Psi_{P}+\rho \tau^{1-\theta} \xi_{H}^{1-\theta} \Psi_{H}+(1-\rho) \tau^{1-\theta} \xi_{L}^{1-\theta} \Psi_{L}\right] \\
& -n_{P} W f_{P}-\left[\rho n_{H}+(1-\rho) n_{L}\right] W f_{X} \\
& +n_{s} \beta \rho\left[n_{H} E V\left(\xi_{H}\right)+\left(1-n_{H}\right) E V(\infty)\right] \\
& +n_{s} \beta(1-\rho)\left[n_{L} E V\left(\xi_{L}\right)+\left(1-n_{L}\right) E V(\infty)\right] \\
= & \left(\frac{\Pi_{0}}{\eta}\right)\left[\Psi_{P}+\rho \tau^{1-\theta} \xi_{H}^{1-\theta} \Psi_{H}+(1-\rho) \tau^{1-\theta} \xi_{L}^{1-\theta} \Psi_{L}\right]+n_{s} \beta E V(\infty) .
\end{aligned}
$$

Similarly, the expected values of an exporter with $\xi=\xi_{L}$ can be rewritten as

$$
E V\left(\xi_{L}\right)=\left(\frac{\Pi_{0}}{\eta}\right)\left[\Psi_{P}+(1-\rho) \tau^{1-\theta} \xi_{H}^{1-\theta} \Psi_{H}+\rho \tau^{1-\theta} \xi_{L}^{1-\theta} \Psi_{L}\right]+n_{s} \beta E V(\infty)
$$

From 22, 24 and 25, we have

$$
\begin{aligned}
E V\left(\xi_{H}\right)-E V(\infty) & =\left(\frac{\Pi_{0}}{\eta}\right)(1-\rho) \tau^{1-\theta}\left(\xi_{L}^{1-\theta} \Psi_{L}-\xi_{H}^{1-\theta} \Psi_{H}\right) \\
E V\left(\xi_{L}\right)-E V(\infty) & =\left(\frac{\Pi_{0}}{\eta}\right) \rho \tau^{1-\theta}\left(\xi_{L}^{1-\theta} \Psi_{L}-\xi_{H}^{1-\theta} \Psi_{H}\right)
\end{aligned}
$$

From (18), 19], 26) and (27), we have the marginal exporters' productivity conditions as

$$
\begin{aligned}
W f_{X} & =\Pi_{0} \tau^{1-\theta} \xi_{H}^{1-\theta} a_{H}+\left(\frac{n_{s} \beta}{\eta}\right) \Pi_{0}(1-\rho) \tau^{1-\theta}\left(\xi_{L}^{1-\theta} \Psi_{L}-\xi_{H}^{1-\theta} \Psi_{H}\right) \\
W f_{X} & =\Pi_{0} \tau^{1-\theta} \xi_{L}^{1-\theta} a_{L}+\left(\frac{n_{s} \beta}{\eta}\right) \Pi_{0} \rho \tau^{1-\theta}\left(\xi_{L}^{1-\theta} \Psi_{L}-\xi_{H}^{1-\theta} \Psi_{H}\right)
\end{aligned}
$$

The masses of non-exporters, $N_{0}$, exporters with $\xi_{H}, N_{H}$, and exporters with $\xi_{L}, N_{L}$, are given by

$$
\begin{aligned}
(30) \quad N_{0}= & {\left[\left(n_{s} N_{0}+N_{E}\right)+\rho n_{s} N_{H}+(1-\rho) n_{s} N_{L}\right]\left(1-n_{H}\right) } \\
& +\left[(1-\rho) n_{s} N_{H}+\rho n_{s} N_{L}\right]\left(1-n_{L}\right) \\
(31) \quad N_{H}= & {\left[\left(n_{s} N_{0}+N_{E}\right)+\rho n_{s} N_{H}+(1-\rho) n_{s} N_{L}\right] n_{H} } \\
(32) \quad N_{L}= & {\left[(1-\rho) n_{s} N_{H}+\rho n_{s} N_{L}\right] n_{L}, } \\
(33) \quad N= & N_{0}+N_{H}+N_{L}
\end{aligned}
$$

where $N$ is the mass of all producers, and $N_{E}$ is the mass of entrants, $N_{E}=\left(1-n_{s}\right) N$. Using the masses 
of producers, we can rewrite (4) with $\sqrt{5}$ and $\sqrt{6}$ as,

$$
\begin{aligned}
1= & \left(\frac{\theta W}{\theta-1}\right)^{1-\theta} N\left(\Psi_{P}+\tau^{1-\theta} \Psi_{X}\right) \\
\Psi_{X}= & \xi_{H}^{1-\theta}\left[\left(\frac{n_{s} N_{0}+N_{E}}{N}\right)+\rho n_{s}\left(\frac{N_{H}}{N}\right)+(1-\rho) n_{s}\left(\frac{N_{L}}{N}\right)\right] \Psi_{H} \\
& +\xi_{L}^{1-\theta}\left[(1-\rho) n_{s}\left(\frac{N_{H}}{N}\right)+\rho n_{s}\left(\frac{N_{L}}{N}\right)\right] \Psi_{L} \\
= & \xi_{H}^{1-\theta} \Psi_{H}\left(\frac{N_{H}}{N n_{H}}\right)+\xi_{L}^{1-\theta} \Psi_{L}\left(\frac{N_{L}}{N n_{L}}\right) \\
= & \xi_{H}^{1-\theta} \Psi_{H}+\left(\xi_{L}^{1-\theta} \Psi_{L}-\xi_{H}^{1-\theta} \Psi_{H}\right)\left(\frac{N_{L}}{N n_{L}}\right)
\end{aligned}
$$

Labor Market Clearing Condition: The total labor in production is given by

$$
L_{P}=\sum_{\xi \in\left\{\xi_{L}, \xi_{H}, \infty\right\}} \int l(z, \xi, f) \varphi_{H, t}(a, \xi) d a=(\theta-1)\left(\frac{\Pi_{0}}{W}\right) N\left(\Psi_{P}+\tau^{1-\theta} \Psi_{X}\right) .
$$

The total labor used for fixed costs in production is given by

(36) $N n_{P} f_{T}=\frac{\Pi_{0}}{W}\left(\frac{\eta-1}{\eta}\right) N \Psi_{P}$.

The total fixed cost in exporting is given by

$$
\begin{aligned}
L_{X}= & {\left[n_{s} N_{0}+N_{E}+\rho n_{s} N_{H}+(1-\rho) n_{s} N_{L}\right] n_{H} f_{X}+\left[(1-\rho) n_{s} N_{H}+\rho n_{s} N_{L}\right] n_{L} f_{X} } \\
= & \frac{\Pi_{0}}{W}\left(\frac{N_{H}}{n_{H}}\right)\left(\frac{\eta-1}{\eta}\right) \tau^{1-\theta} \xi_{H}^{1-\theta} \Psi_{H} \\
& +\frac{\Pi_{0}}{W}\left(\frac{N_{H}}{n_{H}}\right)\left(\frac{n_{s} \beta}{\eta}\right)(1-\rho) \tau^{1-\theta} n_{H}\left(\xi_{L}^{1-\theta} \Psi_{L}-\xi_{H}^{1-\theta} \Psi_{H}\right) \\
& +\frac{\Pi_{0}}{W}\left(\frac{N_{L}}{n_{L}}\right)\left(\frac{\eta-1}{\eta}\right) \tau^{1-\theta} \xi^{1-\theta} \Psi_{L} \\
& +\frac{\Pi_{0}}{W}\left(\frac{N_{L}}{n_{L}}\right)\left(\frac{n_{s} \beta}{\eta}\right) \rho \tau^{1-\theta} n_{L}\left(\xi_{L}^{1-\theta} \Psi_{L}-\xi_{H}^{1-\theta} \Psi_{H}\right) \\
= & \frac{\Pi_{0}}{W} \tau^{1-\theta} N\left[\left(\frac{\eta-1}{\eta}\right) \Psi_{X}+\left(\frac{\beta}{\eta}\right)\left(\Psi_{X}-\xi_{H}^{1-\theta} \Psi_{H}\right)\right]
\end{aligned}
$$

The total labor used for entry is given by

$$
N_{E} f_{E}=\frac{\beta\left(1-n_{s}\right)}{1-n_{s} \beta}\left(\frac{1}{\eta}\right)\left(\frac{\Pi_{0}}{W}\right) N\left(\Psi_{P}+\tau^{1-\theta} \xi_{H}^{1-\theta} \Psi_{H}\right)
$$

The labor market clearing condition is given by

$$
\begin{aligned}
L= & (\theta-1) \frac{\Pi_{0}}{W} N\left(\Psi_{P}+\tau^{1-\theta} \Psi_{X}\right)+\frac{\Pi_{0}}{W}\left(\frac{\eta-1}{\eta}\right) N \Psi_{P} \\
& +\frac{\Pi_{0}}{W} \tau^{1-\theta} N\left[\left(\frac{\eta-1}{\eta}\right) \Psi_{X}+\left(\frac{\beta}{\eta}\right)\left(\Psi_{X}-\xi_{H}^{1-\theta} \Psi_{H}\right)\right] \\
& +\frac{\beta\left(1-n_{s}\right)}{1-n_{s} \beta}\left(\frac{1}{\eta}\right)\left(\frac{\Pi_{0}}{W}\right) N\left(\Psi_{P}+\tau^{1-\theta} \xi_{H}^{1-\theta} \Psi_{H}\right) .
\end{aligned}
$$

Rearranging it, we have

(40) $\frac{W L}{C}=1-\frac{1-\beta}{\theta \eta}-\frac{n_{s} \beta(1-\beta)}{\left(1-n_{s} \beta\right) \theta \eta} S_{0}$, 
where

(41) $S_{0}=\frac{\Psi_{P}+\tau^{1-\theta} \xi_{H}^{1-\theta} \Psi_{H}}{\Psi_{P}+\tau^{1-\theta} \Psi_{X}}$.

Note that $S_{0}^{-1}$ can be interpreted as a measure of an entrant's disadvantage. Clearly, $S_{0}=1$ if $\xi_{H}=\xi_{L}$, and $S_{0}<1$, if $\xi_{H}>\xi_{L}$.

Aggregates: The expenditure on imported goods relative to that on home goods is given by

$$
I M D=\frac{\sum_{\xi \in\left\{\xi_{L}, \xi_{H}\right\}} \int_{a} P_{F}(a, \xi) y_{F}(a, \xi) \varphi_{F}(a, \xi) d a}{\sum_{\xi \in\left\{\xi_{L}, \xi_{H}, \infty\right\}} \int_{a} P_{H}(a, \xi) y_{H}(a, \xi) \varphi_{H}(a, \xi) d a}=\frac{\tau^{1-\theta} \Psi_{X}}{\Psi_{P}}
$$

The share of expenditures on domestic goods is given by

$$
\lambda=\frac{1}{1+I M D}=\frac{\Psi_{P}}{\Psi_{P}+\tau^{1-\theta} \Psi_{X}} .
$$

\section{A.4 Long-Run Growths}

Productivity Thresholds, $a_{P}, a_{H}$, and $a_{L}$ : The productivity thresholds are determined by four equations (11), 23), (28) and (29). With these four equations, we have three equations that determine the productivity thresholds

$$
\begin{aligned}
& \left(\frac{f_{E}}{f_{P}}\right) a_{P}=\left(\frac{\beta}{1-n_{s} \beta}\right)\left(\frac{1}{\eta}\right)\left(\Psi_{P}+\tau^{1-\theta} \xi_{H}^{1-\theta} \Psi_{H}\right) \\
& \left(\frac{f_{X}}{f_{P}}\right) a_{P}=\tau^{1-\theta} \xi_{H}^{1-\theta} a_{H}+\left(\frac{n_{s} \beta}{\eta}\right)(1-\rho) \tau^{1-\theta}\left(\xi_{L}^{1-\theta} \Psi_{L}-\xi_{H}^{1-\theta} \Psi_{H}\right), \\
& \left(\frac{f_{X}}{f_{P}}\right) a_{P}=\tau^{1-\theta} \xi_{L}^{1-\theta} a_{L}+\left(\frac{n_{s} \beta}{\eta}\right) \rho \tau^{1-\theta}\left(\xi_{L}^{1-\theta} \Psi_{L}-\xi_{H}^{1-\theta} \Psi_{H}\right) .
\end{aligned}
$$

From 45) and 46], we have

$$
\xi_{H}^{1-\theta} a_{H}-\xi_{L}^{1-\theta} a_{L}=\left(\frac{n_{s} \beta}{\eta}\right)(2 \rho-1)\left(\xi_{L}^{1-\theta} \Psi_{L}-\xi_{H}^{1-\theta} \Psi_{H}\right)
$$

Note that we should have $\xi_{L}^{1-\theta} \Psi_{L}>\xi_{H}^{1-\theta} \Psi_{H}$ by construction. Thus, we have

(48) $\xi_{H}^{1-\theta} a_{H}>\xi_{L}^{1-\theta} a_{L}$,

and $a_{H}>a_{L}$ with $\xi_{H}>\xi_{L}$. It follows that $\Psi_{H}<\Psi_{L}$ and $n_{H}<n_{L}$. Taking the log-linearization of (47), we have

$$
\widehat{a}_{L}=\left(\frac{\xi_{H}}{\xi_{L}}\right)^{1-\theta}\left(\frac{a_{H}}{a_{L}}\right)\left[\frac{1-n_{s} \beta(2 \rho-1) n_{H}}{1-n_{s} \beta(2 \rho-1) n_{L}}\right] \widehat{a}_{H} .
$$

Since $\xi_{H}^{1-\theta} a_{H}>\xi_{L}^{1-\theta} a_{L}$ and $n_{H}<n_{L}$, we have $\widehat{a}_{L} / \widehat{a}_{H}>1$. Taking the log-linearization of (44) and 45, we have

$$
\begin{aligned}
\widehat{a}_{P}= & -\frac{\tau^{1-\theta} \xi_{H}^{1-\theta} \Psi_{H}}{\eta \Psi_{P}+\tau^{1-\theta} \xi_{H}^{1-\theta} \Psi_{H}}\left[(\theta-1) \widehat{\tau}+(\eta-1) \widehat{a}_{H}\right] \\
\widehat{a}_{P}= & -(\theta-1) \widehat{\tau}+\left(\frac{f_{P}}{f_{X}}\right) \tau^{1-\theta} a_{P}^{-1}\left[\xi_{H}^{1-\theta} a_{H} \widehat{a}_{H}\right. \\
& \left.-\left(\frac{n_{s} \beta}{\eta}\right)(1-\rho)(\eta-1)\left(\xi_{L}^{1-\theta} \Psi_{L} \widehat{a}_{L}-\xi_{H}^{1-\theta} \Psi_{H} \widehat{a}_{H}\right)\right] .
\end{aligned}
$$


Rearranging them with 449 , we have

$$
\begin{aligned}
\widehat{a}_{H} & =\frac{(\theta-1) \eta \Psi_{P}}{(\eta-1) \tau^{1-\theta} \xi_{H}^{1-\theta} \Psi_{H}+\left[\eta \Psi_{P}+\tau^{1-\theta} \xi_{H}^{1-\theta} \Psi_{H}\right]\left(\frac{\zeta_{0}}{\zeta_{1}}\right)} \widehat{\tau} \\
\widehat{a}_{P} & =-\frac{(\theta-1)\left[\zeta_{0}+(\eta-1) \zeta_{1}\right] \tau^{1-\theta} \xi_{H}^{1-\theta} \Psi_{H}}{\eta \zeta_{0} \Psi_{P}+\left[\zeta_{0}+(\eta-1) \zeta_{1}\right] \tau^{1-\theta} \xi_{H}^{1-\theta} \Psi_{H}} \widehat{\tau}
\end{aligned}
$$

where

$$
\begin{aligned}
\zeta_{0} & =1-\frac{n_{s} \beta(1-\rho)\left(n_{L}-n_{H}\right)}{1-n_{s} \beta(2 \rho-1) n_{L}} \\
\zeta_{1} & =\left(\frac{f_{X}}{f_{P}}\right) \tau^{\theta-1} \xi_{H}^{\theta-1}\left(\frac{a_{P}}{a_{H}}\right) \\
& =1+n_{s} \beta(1-\rho) n_{H}\left(\frac{1}{\eta-1}\right)\left[\left(\frac{\xi_{L}}{\xi_{H}}\right)^{1-\theta}\left(\frac{\Psi_{L}}{\Psi_{H}}\right)-1\right]
\end{aligned}
$$

Note that $\zeta_{1}>1$ and $0<\zeta_{0}<1$ since

$$
\zeta_{0}=\frac{1-n_{s} \beta \rho n_{L}+n_{s} \beta(1-\rho) n_{H}}{1-n_{s} \beta(2 \rho-1) n_{L}}>0 .
$$

Clearly, $\widehat{a}_{H} / \widehat{\tau}>0$, and $\widehat{a}_{P} / \widehat{\tau}<0$. From [49, we also have $\widehat{a}_{L} / \widehat{\tau}>0$. That is, with a tariff cut, $\widehat{\tau}<0$, the exporting thresholds $a_{H}$ and $a_{L}$ both fall, but the production threshold $a_{P}$ rises.

From (53), we find that following a cut in the tariff rate, $a_{P}$ falls at the margin less in the model with exporter dynamics than in the model without them, for the same initial trade share and tariff rate. To see that, we can rewrite $(53)$ as

$$
\frac{\widehat{a}_{P}}{\widehat{\tau}}=-(\theta-1)\left[1+\left(\frac{\Psi_{P}}{\tau^{1-\theta} \Psi_{X}}\right) \frac{\frac{\eta \Psi_{X}}{\xi_{H}^{1-\theta} \Psi_{H}}}{1+(\eta-1)\left(\frac{\zeta_{1}}{\zeta_{0}}\right)}\right]^{-1}
$$

From 43 , we have

$$
\frac{\Psi_{P}}{\tau^{1-\theta} \Psi_{X}}=\left(\frac{\lambda}{1-\lambda}\right)
$$

From (35), we have

$$
\frac{\Psi_{X}}{\xi_{H}^{1-\theta} \Psi_{H}}=1+\left(\frac{N_{L}}{N n_{L}}\right)\left[\left(\frac{\xi_{L}}{\xi_{H}}\right)^{1-\theta}\left(\frac{\Psi_{L}}{\Psi_{H}}\right)-1\right]
$$

From (30), 31) and (32), we have the fraction of exporters with $\xi_{H}$ and $\xi_{L}$ as

$$
\begin{aligned}
\left(\frac{N_{L}}{N n_{L}}\right)+\left(\frac{N_{H}}{N n_{H}}\right) & =1, \\
\left(1-\rho n_{s} n_{L}\right)\left(\frac{N_{L}}{N}\right) & =(1-\rho) n_{s}\left(\frac{N_{H}}{N}\right) n_{L},
\end{aligned}
$$

Rearranging them, we have the fraction of producers with $\xi_{L}$ as

$$
\frac{N_{L}}{N n_{L}}=\frac{(1-\rho) n_{s} n_{H}}{1+(1-\rho) n_{s} n_{H}-\rho n_{s} n_{L}} .
$$

So, we have

$$
\frac{\eta \Psi_{X}}{\xi_{H}^{1-\theta} \Psi_{H}}=\eta+\frac{\eta(1-\rho) n_{s} n_{H}}{1+(1-\rho) n_{s} n_{H}-\rho n_{s} n_{L}}\left[\left(\frac{\xi_{L}}{\xi_{H}}\right)^{1-\theta}\left(\frac{\Psi_{L}}{\Psi_{H}}\right)-1\right]
$$


From (54) and (55), we have

$$
\begin{aligned}
1+(\eta-1) \frac{\zeta_{1}}{\zeta_{0}}= & 1+\frac{1-n_{s} \beta(2 \rho-1) n_{L}}{1+n_{s} \beta(1-\rho) n_{H}-n_{s} \beta \rho n_{L}} \\
& \left\{\eta-1+n_{s} \beta(1-\rho) n_{H}\left[\left(\frac{\xi_{L}}{\xi_{H}}\right)^{1-\theta}\left(\frac{\Psi_{L}}{\Psi_{H}}\right)-1\right]\right\} \\
= & \eta+\frac{n_{s} \beta(1-\rho) n_{H}}{1+n_{s} \beta(1-\rho) n_{H}-n_{s} \beta \rho n_{L}}\left[\left(\frac{\xi_{L}}{\xi_{H}}\right)^{1-\theta}\left(\frac{\Psi_{L}}{\Psi_{H}}\right)-1\right] \\
& \left\{\frac{(\eta-1)\left(\frac{n_{L}}{n_{H}}-1\right)}{\left(\frac{\xi_{L}}{\xi_{H}}\right)^{1-\theta}\left(\frac{\Psi_{L}}{\Psi_{H}}\right)-1}+\left[1-n_{s} \beta(2 \rho-1) n_{L}\right]\right\}
\end{aligned}
$$

From (47), we have

$$
1-\left(\frac{\xi_{L}}{\xi_{H}}\right)^{1-\theta}\left(\frac{\Psi_{L}}{\Psi_{H}}\right)\left(\frac{n_{H}}{n_{L}}\right)=n_{s} \beta(2 \rho-1)\left(\frac{1}{\eta-1}\right) n_{H}\left[\left(\frac{\xi_{L}}{\xi_{H}}\right)^{1-\theta}\left(\frac{\Psi_{L}}{\Psi_{H}}\right)-1\right] .
$$

Rearranging it, we have

$$
n_{s} \beta(2 \rho-1) n_{L}=\frac{(\eta-1)\left(\frac{n_{L}}{n_{H}}-1\right)}{\left(\frac{\xi_{L}}{\xi_{H}}\right)^{1-\theta}\left(\frac{\Psi_{L}}{\Psi_{H}}\right)-1}-(\eta-1)
$$

Applying this to 64, we have

$$
1+(\eta-1) \frac{\zeta_{1}}{\zeta_{0}}=\eta+\frac{\eta n_{s} \beta(1-\rho) n_{H}}{1+n_{s} \beta(1-\rho) n_{H}-n_{s} \beta \rho n_{L}}\left[\left(\frac{\xi_{L}}{\xi_{H}}\right)^{1-\theta}\left(\frac{\Psi_{L}}{\Psi_{H}}\right)-1\right] .
$$

We have

$$
\begin{aligned}
1+n_{s} \beta(1-\rho) n_{H}-n_{s} \beta \rho n_{L} & =1+n_{s}(1-\rho) n_{H}-n_{s} \rho n_{L}+(1-\beta) n_{s}\left[\rho n_{L}-(1-\rho) n_{H}\right] \\
& \geq 1+n_{s}(1-\rho) n_{H}-n_{s} \rho n_{L}
\end{aligned}
$$

since $\rho>1 / 2$ and $n_{L}>n_{H}$. This gives

$$
\frac{n_{s} \beta(1-\rho) n_{H}}{1+n_{s} \beta(1-\rho) n_{H}-n_{s} \beta \rho n_{L}}<\frac{n_{s}(1-\rho) n_{H}}{1+n_{s}(1-\rho) n_{H}-n_{s} \rho n_{L}}
$$

Thus, we have

(69) $-\left.\frac{\widehat{a}_{P}}{(\theta-1) \widehat{\tau}}\right|_{\xi_{H}>\xi_{L}}<-\left.\frac{\widehat{a}_{P}}{(\theta-1) \widehat{\tau}}\right|_{\xi_{H}=\xi_{L}}$,

Exporters with $\xi_{L}$ : From we have the fraction of producers with $\xi_{L}$ as

(70) $\frac{N_{L}}{N n_{L}}=\left[1+\frac{1-\rho n_{s} n_{L}}{(1-\rho) n_{s} n_{H}}\right]^{-1}$.

Since $\widehat{a}_{H} / \widehat{\tau}>0$, and $\widehat{a}_{L} / \widehat{\tau}>0$, we have $\widehat{n}_{H} / \widehat{\tau}<0$, and $\widehat{n}_{L} / \widehat{\tau}<0$. Thus, from 70$]$, the fraction of producers with $\xi_{L}$ falls with a rise in the tariff rate,

$$
\frac{\left(\frac{N_{L}}{N n_{L}}\right)}{\widehat{\tau}}<0, \text { and } \frac{\left(\frac{N_{L}}{N}\right)}{\widehat{\tau}}<0
$$


The Trade Elasticity: Log-linearizing (35) gives

$$
\widehat{\Psi}_{X}=\widehat{\Psi}_{H}+\left(1-\frac{\xi_{H}^{1-\theta} \Psi_{H}}{\Psi_{X}}\right)\left\{\left(\frac{\widehat{N_{L}}}{N n_{L}}\right)+\left[\frac{\left(\frac{\xi_{L}}{\xi_{H}}\right)^{1-\theta}\left(\frac{\Psi_{L}}{\Psi_{H}}\right)}{\left(\frac{\xi_{L}}{\xi_{H}}\right)^{1-\theta}\left(\frac{\Psi_{L}}{\Psi_{H}}\right)-1}\right]\left(\widehat{\Psi}_{L}-\widehat{\Psi}_{H}\right)\right\}
$$

We have

$$
\begin{aligned}
\frac{\widehat{\Psi}_{H}}{\widehat{\tau}} & =-(\eta-1) \frac{\widehat{a}_{H}}{\widehat{\tau}}<0, \\
\frac{\left(\frac{N_{L}}{N n_{L}}\right)}{\widehat{\tau}} & <0 \\
\frac{\widehat{\Psi}_{L}-\widehat{\Psi}_{H}}{\widehat{\tau}} & =-(\eta-1) \frac{\left(\widehat{a}_{L}-\widehat{a}_{H}\right)}{\widehat{\tau}} \\
& =-(\eta-1)\left\{\left(\frac{\xi_{H}}{\xi_{L}}\right)^{1-\theta}\left(\frac{a_{H}}{a_{L}}\right)\left[\frac{1-n_{s} \beta(2 \rho-1) n_{H}}{1-n_{s} \beta(2 \rho-1) n_{L}}\right]-1\right\} \frac{\widehat{a}_{H}}{\widehat{\tau}}<0 .
\end{aligned}
$$

Thus, we have $\frac{\widehat{\Psi}_{X}}{\widehat{\tau}}<\frac{\widehat{\Psi}_{H}}{\widehat{\tau}}<0$. From 51 , we have

(76) $\widehat{a}_{P}=-(\theta-1) \widehat{\tau}+\left(\frac{\zeta_{0}}{\zeta_{1}}\right) \widehat{a}_{H}$.

Using 72 and 76 , the trade elasticity $\varepsilon$ is given by

$$
\begin{aligned}
\varepsilon= & \frac{\left(\frac{\widehat{\Psi_{P}}}{\tau^{1-\theta} \Psi_{X}}\right)}{\widehat{\tau}} \\
= & \eta(\theta-1)+(\eta-1)\left(1-\frac{\zeta_{0}}{\zeta_{1}}\right) \frac{\widehat{a}_{H}}{\widehat{\tau}} \\
& -\left(1-\frac{\xi_{H}^{1-\theta} \Psi_{H}}{\Psi_{X}}\right)\left\{\frac{\left(\frac{N_{L}}{N n_{L}}\right)}{\widehat{\tau}}+\left[\frac{\left(\frac{\xi_{L}}{\xi_{H}}\right)^{1-\theta}\left(\frac{\Psi_{L}}{\Psi_{H}}\right)}{\left(\frac{\xi_{L}}{\xi_{H}}\right)^{1-\theta}\left(\frac{\Psi_{L}}{\Psi_{H}}\right)-1}\right]\left(\frac{\widehat{\Psi}_{L}-\widehat{\Psi}_{H}}{\widehat{\tau}}\right)\right\}
\end{aligned}
$$

Since $0<\zeta_{0}<1, \zeta_{1}>1, \frac{\widehat{a}_{H}}{\widehat{\tau}}>0, \frac{\left(\frac{\widehat{N_{L}}}{N_{L}}\right)}{\widehat{\tau}}<0$, and $\left(\frac{\widehat{\Psi}_{L}-\widehat{\Psi}_{H}}{\widehat{\tau}}\right) \leq 0$, we have $\varepsilon>\eta(\theta-1)$. Note that when $\xi_{H}=\xi_{L}$, the elasticity becomes $\left.\varepsilon\right|_{\xi_{H}=\xi_{L}}=\eta(\theta-1)$. Thus, the model with exporter dynamics has a greater trade elasticity compared to the model without it, $\xi_{H}=\xi_{L}$.

Entrant's disadvantage $\left(S_{0}^{-1}\right)$ : The entrant's disadvantage is measured with $S_{0}^{-1}$ in 41 . Log-linearizing the equation gives

$$
\begin{aligned}
\widehat{S}_{0}= & \frac{\Psi_{P} \widehat{\Psi}_{P}+\tau^{1-\theta} \xi_{H}^{1-\theta} \Psi_{H}\left(-(\theta-1) \widehat{\tau}+\widehat{\Psi}_{H}\right)}{\Psi_{P}+\tau^{1-\theta} \xi_{H}^{1-\theta} \Psi_{H}}-\frac{\Psi_{P} \widehat{\Psi}_{P}+\tau^{1-\theta} \Psi_{X}\left(-(\theta-1) \widehat{\tau}+\widehat{\Psi}_{X}\right)}{\Psi_{P}+\tau^{1-\theta} \Psi_{X}} \\
= & \left(\Psi_{P}+\tau^{1-\theta} \xi_{H}^{1-\theta} \Psi_{H}\right)^{-1}\left(\Psi_{P}+\tau^{1-\theta} \Psi_{X}\right)^{-1} \\
& \left\{\tau^{1-\theta}\left(\Psi_{X}-\xi_{H}^{1-\theta} \Psi_{H}\right) \Psi_{P} \widehat{\Psi}_{P}+\tau^{1-\theta}\left[\Psi_{X}-\xi_{H}^{1-\theta} \Psi_{H}\right] \Psi_{P}(\theta-1) \widehat{\tau}\right. \\
& \left.-\tau^{1-\theta} \Psi_{X} \widehat{\Psi}_{X}\left[\Psi_{P}\left(1-\frac{\xi_{H}^{1-\theta} \Psi_{H}}{\Psi_{X}} \widehat{\Psi}_{H}\right)+\tau^{1-\theta} \xi_{H}^{1-\theta} \Psi_{H}\left(1-\frac{\widehat{\Psi}_{H}}{\widehat{\Psi}_{X}}\right)\right]\right\} .
\end{aligned}
$$


Since $\widehat{\Psi}_{P} / \widehat{\tau}>0, \widehat{\Psi}_{X} / \widehat{\tau}<0$, and $0<\widehat{\Psi}_{H} / \widehat{\Psi}_{X}<1$, we have $\widehat{S}_{0} / \widehat{\tau}>0$. That is, the entrant's disadvantage, $S_{0}^{-1}$, rises with a tariff cut.

Labor Share of GDP $(W L / C)$ : From the labor market clearing condition 40), we have

(79) $\frac{W L}{C}=b_{0}-b_{1} S_{0}$,

where $b_{0}=1-\left(\frac{1-\beta}{\theta \eta}\right)>0$, and $b_{1}=\frac{n_{s} \beta(1-\beta)}{\left(1-n_{s} \beta\right) \eta \theta}$. Note that $b_{1}>0$ if $\beta \in(0,1)$ and $b_{1}=0$ if $\beta=1$. Thus the trade liberalization, $\tau=1$ from $\tau>1$, raises the labor share of GDP, $W L / C$, with a rise in the entrant's disadvantage, $S_{0}^{-1}$.

Investment on Establishment Capital $(N)$ : From the entry condition (23) and the price index (34), we have

$$
\begin{aligned}
W f_{E} & =\left(\frac{\beta}{1-n_{s} \beta}\right)\left(\frac{1}{\eta \theta}\right) \frac{C}{N}\left(\frac{\Psi_{P}+\tau^{1-\theta} \xi_{H}^{1-\theta} \Psi_{H}}{\Psi_{P}+\tau^{1-\theta} \Psi_{X}}\right) \\
& =\left(\frac{\beta}{1-n_{s} \beta}\right)\left(\frac{1}{\eta \theta}\right) \frac{C S_{0}}{N}
\end{aligned}
$$

Using (79), we have

(81) $N=\left(\frac{\beta}{1-n_{s} \beta}\right)\left(\frac{1}{\eta \theta}\right)\left(\frac{L}{f_{E}}\right)\left(\frac{S_{0}}{b_{0}-b_{1} S_{0}}\right)$.

Since $S_{0}$ falls with the trade liberalization, the mass of producers, $N$, falls, $\widehat{N} / \widehat{\tau}>0$.

Wage Rate $(W)$ : From the price index (34), we have

(82) $W^{\theta-1} \propto N\left(\Psi_{P}+\tau^{1-\theta} \Psi_{X}\right)$,

where $\propto$ denotes 'proportional to'. From the entry condition (23) and the marginal producer condition (11), we have

(83) $a_{P} \propto \Psi_{P}+\tau^{1-\theta} \xi_{H}^{1-\theta} \Psi_{H}$.

We can rewrite it as

(84) $\Psi_{P} \propto\left(\Psi_{P}+\tau^{1-\theta} \xi_{H}^{1-\theta} \Psi_{H}\right)^{-(\eta-1)}$.

So, we have

$$
\begin{aligned}
\frac{\Psi_{P}}{\Psi_{P}+\tau^{-\theta} \xi_{H}^{1-\theta} \Psi_{H}} & =\frac{\lambda}{S_{0}} \\
& \propto\left(\Psi_{P}+\tau^{1-\theta} \xi_{H}^{1-\theta} \Psi_{H}\right)^{-\eta}
\end{aligned}
$$

This gives

$$
\begin{aligned}
\Psi_{P}+\tau^{1-\theta} \Psi_{X} & =\lambda^{-1} \Psi_{P} \\
& \propto\left(S_{0}\right)^{-\frac{\eta-1}{\eta}} \lambda^{-\frac{1}{\eta}}
\end{aligned}
$$


With 81 and 86, , 82, can be rewritten as

$$
W^{\theta-1} \propto\left(b_{0}-b_{1} S_{0}\right)^{-1}\left(\frac{S_{0}}{\lambda}\right)^{\frac{1}{\eta}}
$$

or

(88) $W \propto\left(b_{0}-b_{1} S_{0}\right)^{-\frac{1}{\theta-1}}\left(\frac{S_{0}}{\lambda}\right)^{\frac{1}{\eta(\theta-1)}}$.

So, following the trade liberalization, an increase in the entrant's disadvantage, $S_{0}^{-1}$ lowers the wage growth. Having positive discount rate, $\beta<1$ and $b_{1}>0$, further reduces the growth of the wage rate.

Consumption $(C)$ : Using $(79)$ and $(88)$, consumption can be rewritten as

$$
\begin{aligned}
C & \propto\left(\frac{C}{W}\right) W \\
& \propto\left[\frac{S}{b_{0}-b_{1} S_{0}}\right]\left(b_{0}-b_{1} S_{0}\right)^{-\frac{1}{\theta-1}}\left(\frac{S_{0}}{\lambda}\right)^{\frac{1}{\eta(\theta-1)}} \\
& \propto\left(b_{0}-b_{1} S_{0}\right)^{-\frac{\theta}{\theta-1}}\left(\frac{S_{0}}{\lambda}\right)^{\frac{1}{\eta(\theta-1)}}
\end{aligned}
$$

Following the trade liberalization, a fall in the share of expenditures on domestic goods $\lambda$ raises the welfare. However, the increase in the entrant's disadvantage, $S_{0}^{-1}$ reduces the welfare gains. If the discount rate is positive, $\beta<1$ and $b_{1}>0$, the welfare gains are further reduced because a fall in $S_{0}$ lowers the gains additionally through a fall in the mass of producers.

Long-run Welfare Gains with Same Trade Growth: Equation $(89)$ shows the relationship between the trade growth, $\lambda^{-1}$, and the long run welfare gains, and how the entrant's disadvantage $S_{0}^{-1}$ affect the long run consumption growth. However, it is not clear how the model predicts the long run growth once the model is calibrated to match the trade growth with same tariffs $\tau$ and initial trades. To find it out we can rewrite the consumption equation as follows. From $(79), 82$ and 83 we have

$$
\begin{aligned}
(90) C & \propto\left(\frac{C}{W}\right)\left(\frac{N a_{P}}{S_{0}}\right)^{\frac{1}{\theta-1}} \\
& \propto\left(\frac{1}{b_{0}-b_{1} S_{0}}\right)\left[\left(b_{0}-b_{1} S_{0}\right)^{-1} a_{P}\right]^{\frac{1}{\theta-1}} \\
& \propto\left(b_{0}-b_{1} S_{0}\right)^{-\frac{\theta}{\theta-1}} a_{P}^{\frac{1}{\theta-1}} .
\end{aligned}
$$

Note that $-\left.\frac{\widehat{a}_{P}}{(\theta-1) \widehat{\tau}}\right|_{\xi_{H}}>\xi_{L}<-\left.\frac{\widehat{a}_{P}}{(\theta-1) \widehat{\tau}}\right|_{\xi_{H}=\xi_{L}}$ with the same trade shares $\lambda$, and $S_{0}$ falls with a tariff cut. Thus, we have

$$
(91)-\left.\frac{\widehat{C}}{\widehat{\tau}}\right|_{\xi_{H}>\xi_{L}}<-\left.\frac{\widehat{C}}{\widehat{\tau}}\right|_{\xi_{H}=\xi_{L}} .
$$

Thus, with a trade liberalization, the long run welfare gains are smaller with exporter dynamics relative to those without under the same trade growth. The key reason for the result is that with the exporter dynamics, there exists a entrant's disadvantage, $S_{0}^{-1}$. When the disadvantage rises with the trade liberalization, the investment on the establishment capital, $N$, falls. This reduces the welfare gains. Additionally, with a fall in the mass of producers, the adjustment of the production threshold $a_{P}$ becomes smaller compared to the case without a change in $N$ (with $\xi_{H}=\xi_{L}$ ). This smaller adjustment of $a_{P}$ reduces the long run welfare 
gains.

\section{References}

[1] Alessandria, G. and H. Choi (2011): "Analytical Appendix to Establishment Heterogeneity, Exporter Dynamics, and the Effects of Trade Liberalization," Federal Reserve Bank of Philadelphia, Working Paper, April 2011. 